

\title{
A CRITICAL ANALYSIS OF INTERFACE CONSTITUTIVE MODELS FOR THE SIMULATION OF DELAMINATION IN COMPOSITES AND FAILURE OF ADHESIVE BONDS
}

\author{
Anton Matzenmiller, Sebastian Gerlach and Mark Fiolka
}

\begin{abstract}
Delamination in layered composites and debonding in adhesive joints are modeled and analyzed using interfacial mechanics, consisting of interface elements for the kinematical assumption and tractionseparation equations for the constitutive model. Material equations are presented for the inelastic behavior of pure and ductile-modified epoxy resins, used for the matrix phase of the composite and in a chemically modified form for the adhesive in bonded structures.

Two different modeling approaches are proposed. The first is a brittle fracture model with a stressbased failure criterion and rate-dependent strength parameters together with a mixed-mode energy criterion for the interaction of the three different modes of failure. The second makes use of an elastic-plastic approach with a traction-separation equation for ductile materials and rate-dependent yield stresses.

Standard tests for the delamination of layered composites under various modes of failure are simulated by making use of the interface element for bonding/debonding. The model for the inelastic behavior of a thin layer of the structural adhesive is validated up to fracture for various modes of failure due to pure and combined loading in the normal and shear directions. Therefore, the relevant part of the experimental setup for the testing is meshed with finite elements and the results of the simulation are compared to the corresponding test data.
\end{abstract}

\section{Introduction}

Delamination in layered composites and debonding in adhesive joints are caused by crack initiation and growth, since epoxy resin is often used as the matrix material of the reinforced composite and in a chemically modified form as the adhesive for the bonding of structural components. With regard to the mathematical description of both failure mechanisms, that is, the separation of the laminae and the breaking of the adhesive layer in the joints, interfacial mechanics may be employed with interface elements for the kinematics and traction-separation equations of the constitutive formulation. Therefore, constitutive equations for the inelastic behavior of pure and ductile-modified epoxy resins are needed in

Keywords: adhesive models, structural bonding, delamination, crash analysis, interface element, traction-separation model, adhesively bonded joints, simulation of failure, plasticity, mixed-mode fracture.

Parts of the experimental results presented stem from the research project [Schlimmer et al. 2008], coordinated and financed by the Forschungsvereinigung Stahlanwendung e.V., Düsseldorf, with resources from the Stiftung Stahlanwendungsforschung, Essen. The participants of this project are the Institut für Werkstofftechnik, Universität Kassel, the Institut für Mechanik, Universität Kassel, the Laboratorium für Werkstoff- und Fügetechnik, Universität Paderborn, the Lehrstuhl für Technische Mechanik, Universität Paderborn, the Institut für Füge- und Schweißtechnik, Universität Braunschweig, the Fraunhofer Institut für Fertigungstechnik, Bremen, the Fraunhofer Institut für Werkstoffmechanik, Freiburg, and the Fraunhofer Institut für Kurzzeitdynamik, Freiburg. 
addition to the interface elements for the effective modeling of the cohesive zone in the crashworthiness analysis of layered composites as well as adhesively bonded structures.

In order to prevent sudden brittle fracture at low strain magnitudes, typical adhesives, made of epoxy resin, are toughened by admixing tiny particles of elastomeric substances in order to make the duromeric matrix more ductile. These structural adhesives become strain rate dependent and withstand large deformations. They are used in the bonded joints of car bodies. Tests on bulk specimens of toughened adhesives show permanent deformations after unloading, if the material is strained beyond a critical limit.

The theory of interfacial mechanics is well suited for the modeling and analysis of delamination in layered composite structures and failure of adhesive joints in assembled components. The characteristic feature of interfacial mechanics is the use of only those three stress components, which act on the interface and, thus, on the plane of failure. The constitutive equations are formulated in terms of the displacement discontinuities across the interface.

The failure analysis of adhesive joints in assembled structures requires a fine discretization of the adhesive layer in the thickness direction in order to describe the state of stress precisely. However, for the crashworthiness analysis of complete vehicle bodies, tiny finite elements are undesirable, since they require a small critical time step for the simulation of the entire structure with explicit integration schemes for the equations of motion. Crash simulation with solid elements for thin adhesive layers in complete car body models is numerically still too elaborate, if no additional measures, like mass-scaling, are taken to increase the critical step length of time. Thus, interface elements with very small or zero thickness are superior for the modeling of thin adhesive layers. Then, the critical time step is no longer controlled by the Friedrichs-Levy criterion of the solid elements for the adhesive layer but rather by the neighbouring shell or solid elements, applied for the adjacent steel structures.

Two different modeling approaches for the delamination of layered materials and joints with thin adhesive layers are taken from the literature. The first is a fracture model, founded on the work of Barenblatt [1959] and Dugdale [1960], with a stress-based failure criterion and rate-dependent strength parameters together with a mixed-mode energy criterion for the interaction of the three different modes of failure. The second makes use of an elastic-plastic description with a traction-separation equation for ductile materials as proposed by $\mathrm{Su}$ et al. [2004].

Due to the similarity between thin layers in structural components and laminated fiber composites, analysis using interface models can be used in both cases. The finite element calculation of fracture or delamination of specimens in different modes of failure under quasistatic and crash loading is demonstrated with various numerical examples.

\section{Cohesive zone models}

The experimental investigations performed in [Schlimmer et al. 2008] at joints, bonded with crashresistant adhesives, show that the fracture of the bonding is dominated by cohesive failure, that is, the crack initiation and growth takes place within the cohesive zone (see Section 5). Modelling with one element through the thickness of the adhesive layer is numerically sufficient for the purposes of crashworthiness analysis of complex structural assemblages, because only the effective mechanical behavior of the bonding is important for the vehicle simulation, not the complete three-dimensional fine stress resolution 
in the adhesive layer. Modelling with interface elements is justified, since the compliant adhesive bond between the stiff sheet metal is nearly inextensible and shear rigid in the plane tangential to the adhesive layer. Thus, interfacial mechanics are an efficient approach to modeling adhesive layers as they are widely accepted for the delamination analysis of layered composite structures.

2A. Interface element. Interface elements were originally developed for the description of the delamination process in composite materials [Beer 1985; Mi et al. 1998; Schellekens and de Borst 1993]. Contrary to the usual finite element concept, the primary kinematical variable of the interface element is the displacement jump vector $\boldsymbol{\Delta}$ instead of the strain tensor, as is typical for volumetric continuum elements. The element has three degrees of freedom at each node and consists of a total of eight nodes with four nodes on the upper and lower sides of the interface. The displacement field in the length and transverse directions of the interface is assumed to be bilinear. Full integration with four Gauss points is performed. The element has no stiffness in the membrane direction. Pronounced locking effects could not be observed so far.

2B. Mixed-mode extension of the Hillerborg fracture model. The constitutive behavior for fracture of the adhesive is formulated between the interface stresses $t_{i}$ and the displacement jumps $\Delta_{i}$, which represent the differences of the displacement components in the normal and tangential directions of the two neighbouring surfaces of the adherents. For the description of the softening behavior in interfaces various models have been presented in the literature; for example, Barenblatt [1959] developed a damage model for brittle interfaces. The traction-separation equations are formulated for the three failure modes of fracture mechanics by means of the dissipated energy during the opening of the interface:

$$
\varphi_{\text {Ic }}=\int t_{3} d \Delta_{3}, \quad \varphi_{\text {IIc }}=\int t_{1} d \Delta_{1}, \quad \varphi_{\text {IIIc }}=\int t_{2} d \Delta_{2},
$$

where $\mathscr{\varphi}_{\text {Ic }}, \mathscr{\varphi}_{\text {IIc }}$, and $\mathscr{\varphi}_{\text {IIIc }}$ are the critical energy release rates of the three well-known modes of fracture. The interface traction as a function of the crack opening in the process zone is unknown and must be supposed unless better experimental information is available, as given by [Andersson and Stigh 2004]. Different assumptions for the distribution of the traction-separation equation are discussed in the literature. An example is the bilinear model of Hillerborg et al. [1976] for brittle interfaces, which combines linear elasticity with brittle fracture (see Figure 1).

The adhesive joint behaves linearly elastically up to the stress maximum:

$$
\boldsymbol{t}=\boldsymbol{K} \boldsymbol{\Delta}, \quad \text { with } \quad \boldsymbol{K}=\left[\begin{array}{ccc}
K_{n} & 0 & 0 \\
0 & K_{t} & 0 \\
0 & 0 & K_{t}
\end{array}\right]
$$

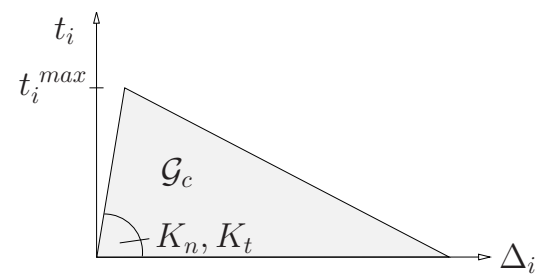

Figure 1. Bilinear course of interface traction versus displacement discontinuity. 
The same relation holds with reduced stiffness values for unloading and reloading, if the interface has started softening. The failure initiation of the interface is determined here by a mixed-mode stress criterion [Brewer and Lagace 1988]:

$$
\sqrt{\left(\frac{t_{1}}{t_{1}^{\max }}\right)^{2}+\left(\frac{t_{2}}{t_{2}^{\max }}\right)^{2}+\left(\frac{\left\langle t_{3}\right\rangle}{t_{3}^{\max }}\right)^{2}}=1 .
$$

The interaction of the three different modes of fracture is accounted for by a mixed-mode energy criterion [Whitcomb 1986]:

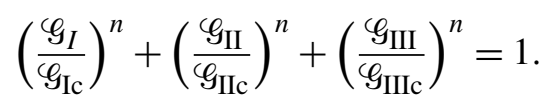

The implementation of the model into a commercial finite element code and the application of the mixedmode formulation with a bilinear stress-strain diagram were presented first by Dávila and Camanho [2001] (see also [Pinho et al. 2006]). In the present paper, the model is extended to rate-dependency and implemented into the commercial FE code LS-DYNA [DYNA 2006], since structural adhesives show rate-dependent material behavior even under the moderate strain rates encountered in the crashworthiness analysis of bonded structural components - see the test data in Section 5A.

In order to take rate-dependent material behavior into account, the mixed-mode fracture model is extended here according to the proposal by Johnson and Cook [1983] for a rate-dependent yield limit. Its application to the brittle fracture model is based on the scaling of the failure stress components $\left(t_{i}^{\max }\right)_{0}$ of the rate-independent limit case with the logarithm of the rate of the effective displacement discontinuity $\dot{\Delta}_{v}$, defined as

$$
t_{1}^{\max }=\left(t_{1}^{\max }\right)_{0}\left(1+C\left\langle\ln \frac{\dot{\Delta}_{v}}{\dot{\Delta}_{0}}\right\rangle\right), \quad t_{3}^{\max }=\left(t_{3}^{\max }\right)_{0}\left(1+C\left\langle\ln \frac{\dot{\Delta}_{v}}{\dot{\Delta}_{0}}\right\rangle\right),
$$

with the material parameter $C$, and in the Macaulay brackets $\langle\cdot\rangle$ the reference value of the jump velocity $\dot{\Delta}_{0}$, which must be identified from the experimental results:

$$
\dot{\Delta}_{v}=\sqrt{\dot{\Delta}_{1}^{2}+\dot{\Delta}_{2}^{2}+\dot{\Delta}_{3}^{2}} \text {. }
$$

It is assumed that the rates of the effective displacement discontinuity $\dot{\Delta}_{v}$ below the reference value $\dot{\Delta}_{0}$ do not contribute to the rate-dependency of the strength parameters for the adhesive.

2C. Tvergaard-Hutchinson fracture model. Tvergaard and Hutchinson proposed one of the first interface failure models for the analysis of fractures in the cohesive zone. The model is widely accepted and used for cohesive zone analysis, since it is available in commercial finite element codes (for example, LS-DYNA [DYNA 2006]). The model of Tvergaard and Hutchinson [1994], based on the ductile fracture concept of Dugdale [1960], possesses a trilinear distribution of the interface traction with regards to the effective crack opening displacement, which is taken as a measure for the damage $\Lambda$ (see Figure 2), defined as

$$
\Lambda=\sqrt{\left(\frac{\Delta_{1}}{\Delta_{1}^{\max }}\right)^{2}+\left(\frac{\left\langle\Delta_{3}\right\rangle}{\Delta_{3}^{\max }}\right)^{2}},
$$

where $\Delta_{1}^{\max }$ and $\Delta_{3}^{\max }$ are the critical crack opening displacements in the tangential and normal directions. However, no permanent displacement jumps in the sense of plasticity are taken into account. Interaction 


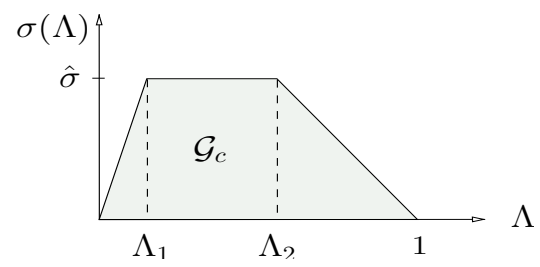

Figure 2. Trilinear course of interface stress $\sigma$ versus damage $\Lambda$.

of fracture modes I and II is inherent in the formulation, which may be extended to mode III in an analogous manner.

The components $t_{i}$ of the stress vector on the interface are derived from a free energy density function [Tvergaard and Hutchinson 1996, equation (1.2)] where the parameter for the damage $\Lambda$ is defined by means of the components $\Delta_{1}$ and $\Delta_{3}$ of the displacement discontinuity vector. The interface stresses are given by the derivatives of the free energy density function with respect to the associated components $\Delta_{i}$ of the crack opening:

$$
t_{3}=\frac{\sigma(\Lambda)}{\Lambda} \frac{\Delta_{3}}{\Delta_{3}^{\max }}, \quad t_{1}=\frac{\sigma(\Lambda)}{\Lambda} \frac{\Delta_{3}^{\max }}{\Delta_{1}^{\max }} \frac{\Delta_{1}}{\Delta_{1}^{\max }}
$$

Hence, the critical energy release rate $\mathscr{G}_{c}$ becomes:

$$
\mathscr{G}_{c}=\frac{1}{2} \hat{\sigma} \Delta_{3}^{\max }\left(1-\Lambda_{1}+\Lambda_{2}\right)
$$

2D. Elastic-plastic interface model. Su et al. [2004] developed an elastic-plastic interface model with softening, which accounts for elastic and irreversible inelastic displacement jumps prior to failure. In this paper the model is improved with respect to hardening and softening and is extended to rate-dependency. It is applied to the analysis of joints, bonded with toughened ductile adhesives under combined loading of shear and tension. Unlike in [Su et al. 2004], the model is validated here for the case of combined tension and shear loading. No information about the model's performance for combined loading is given in [Su et al. 2004]. The constitutive behavior is formulated between the three components of the interface stress vector $t_{i}$ and the components of the displacement jump vector across the adherent layer $\Delta_{i}$. Based on the additive decomposition of the displacement jump vector into elastic and plastic parts, $\boldsymbol{\Delta}=\boldsymbol{\Delta}^{e}+\boldsymbol{\Delta}^{p}$, the elasticity assumption for the calculation of the interface stress vector leads to

$$
\boldsymbol{t}=\boldsymbol{K} \boldsymbol{\Delta}^{e}=\boldsymbol{K}\left(\boldsymbol{\Delta}-\boldsymbol{\Delta}^{p}\right),
$$

with the two-dimensional elastic stiffness tensor $\boldsymbol{K}$ of the interface as given in (2-2). The interface stress vector $\boldsymbol{t}$ may be decomposed into normal and tangential parts, $\boldsymbol{t}_{n}=(\boldsymbol{t} \cdot \boldsymbol{n}) \boldsymbol{n}$ and $\boldsymbol{t}_{t}=\boldsymbol{t}-\boldsymbol{t}_{n}$. The effective shear stress $\tau=\sqrt{\boldsymbol{t}_{t} \cdot \boldsymbol{t}_{t}}$ in the interface is the resultant stress of the two tangential traction components. The elastic domain is bounded by two yield curves with functions $f^{(1)}$ and $f^{(2)}$ for a two surface plasticity interface model. The yield conditions in the normal (1) and shear (2) modes are

$$
\begin{aligned}
& f^{(1)}=t_{n}-Y^{(1)} \leq 0, \\
& f^{(2)}=\tau+\mu t_{n}-Y^{(2)} \leq 0,
\end{aligned}
$$


with the yield stress in the normal, $Y^{(1)}$, and tangential, $Y^{(2)}$, directions. The variable $\mu$ in (2-11) can be interpreted as the friction parameter of the Coulomb model, describing the interaction between stresses in the normal and tangential directions at yielding.

The rate of the plastic displacement jump is defined by the flow rule:

$$
\dot{\Delta}^{p}=\sum_{i=1}^{2} \lambda^{(i)} \boldsymbol{m}^{(i)}
$$

with an associated flow vector in tension $\boldsymbol{m}^{(1)}=\boldsymbol{n}^{(1)}$ and a nonassociated flow vector in shear

$$
\boldsymbol{m}^{(2)}=\frac{\boldsymbol{t}_{t}}{\tau} \neq \boldsymbol{n}^{(2)},
$$

where $\boldsymbol{n}^{(i)}$ is the normal to the yield surface $f^{(i)}$. The variable $\lambda^{(i)}$ is the plastic multiplier in the flow rule for mode $(i)$. It has nothing to do with the $\Lambda$ of Section $2 \mathrm{C}$ in the Tvergaard-Hutchinson model.

Hardening or softening due to either mode of yielding is introduced into the model by means of evolution equations for the change of the current yield stresses $Y^{(i)}$ in [Su et al. 2004]. Here, the yield stresses are given as

$$
Y^{(i)}=\hat{Y}^{(i)}(\bar{\gamma})
$$

in each mode of plastic flow as a function of the equivalent plastic displacement jump $\bar{\gamma}$, introduced as the weighted sum of the time integrated plastic multipliers $\gamma^{(i)}$ :

$$
\bar{\gamma}:=\sqrt{\left(\gamma^{(1)}\right)^{2}+\beta\left(\gamma^{(2)}\right)^{2}},
$$

with $\beta$ as an appropriately identified mode interaction parameter, and where

$$
\gamma^{(i)}:=\int_{0}^{t} \lambda^{(i)}(\tau) d \tau
$$

For the analysis of the peel and KS-II (see Section 5D) tests, the experimental data in Figure 9 are approximated by piecewise linear yield curves for tension $(\alpha=0)$ and slow, uniform loading in pure torsion $(\alpha=\infty)$ :

$$
Y^{(1)}=\hat{Y}^{(1)}\left(\Delta_{n}^{P}\right)=Y_{0}^{(1)}+H^{(1)}(\bar{\gamma}) \Delta_{n}^{P}, \quad Y^{(2)}=\hat{Y}^{(2)}\left(\Delta_{t}^{P}\right)=Y_{0}^{(2)}+H^{(2)}(\bar{\gamma}) \sqrt{\beta} \Delta_{t}^{P} .
$$

The kinematical variables $\Delta_{n}^{P}=\Delta_{3}^{P}$ and $\Delta_{t}^{P}=\sqrt{\left(\Delta_{1}^{P}\right)^{2}+\left(\Delta_{2}^{P}\right)^{2}}$ are respectively the normal and resultant shear components of the plastic displacement jump vector $\Delta^{P}$. The material quantities $H^{(1)}$ and $H^{(2)}$ are the hardening parameters $H_{\text {hard }}^{(1)}$ and $H_{\text {hard }}^{(2)}$ identified as the inclinations of the yield curves in the hardening range. Likewise, $H_{\text {soft }}^{(1)}$ and $H_{\text {soft }}^{(2)}$ denote the slopes of the straight lines through the data in the successive softening range. Three different cases can be distinguished for the hardening quantities $H^{(i)}(\bar{\gamma})$, depending on the state of the effective plastic displacement jump $\bar{\gamma}$ :

$$
H^{(i)}(\hat{\gamma})= \begin{cases}H_{\text {hard }}^{(i)} & \text { if } \bar{\gamma}<\bar{\gamma}_{\text {crit }}, \\ H_{\text {soft }}^{(i)} & \text { if } \bar{\gamma}_{\text {crit }} \leq \bar{\gamma}<\bar{\gamma}_{\text {fail }} \text { and } f^{(i)}>0, \\ 0 & \text { if } \bar{\gamma} \geq \bar{\gamma}_{\text {fail }} .\end{cases}
$$


In the first case, the equivalent plastic displacement jump $\bar{\gamma}$ is smaller than the given critical displacement jump $\bar{\gamma}_{\text {crit }}$ and the adhesive layer is still in the state of hardening. If the variable $\bar{\gamma}$ is greater than the critical displacement jump, then softening of the adhesive takes place. The interface fails when the variable $\bar{\gamma}$ is equal to the displacement jump at failure $\bar{\gamma}_{\text {fail }}$, which follows from the softening moduli $H_{\text {soft }}^{(1)}$ and $H_{\text {soft }}^{(2)}$. Note that the softening moduli are included in the model as material parameters and $\bar{\gamma}_{\text {fail }}$ is calculated from them.

In this paper the elastic-plastic traction-separation equation is extended to rate-dependency by defining the initial yield stresses $Y_{0}^{(1)}$ and $Y_{0}^{(2)}$ in the normal and tangential directions similar to the proposal of Johnson and Cook [1983] for a rate-dependent yield limit:

$$
Y^{(1)}=Y_{0}^{(1)}\left(1+C\left\langle\ln \frac{\dot{\Delta}_{v}}{\dot{\Delta}_{0}}\right\rangle\right)+H_{\text {hard }}^{(1)} \Delta_{n}^{P}, \quad Y^{(2)}=Y_{0}^{(2)}\left(1+C\left\langle\ln \frac{\dot{\Delta}_{v}}{\dot{\Delta}_{0}}\right\rangle\right)+H_{\text {hard }}^{(2)} \Delta_{t}^{P} .
$$

The material parameter $C$ and the reference rate of the displacement jump $\dot{\Delta}_{0}$ must be determined experimentally. The variables $Y_{0}^{(i)}$ are the initial yield stresses according to (2-16) for the two modes of plastic flow and the variable $\dot{\Delta}_{v}$ is the rate of the effective displacement jump as given in (2-6).

\section{Time step control for explicit integration of equations of motion}

The size of the critical time step for the conditionally stable explicit schemes has to be estimated for the numerical time integration of the equations of motion. The inverse of the largest eigenfrequency of the linear system of second order ordinary differential equations limits the maximum allowable time step, which is slightly reduced and then used for the step-by-step integration of the nonlinear system of the equations of motion. The largest eigenfrequency of the linear system is usually not known, since it is practically impossible to repeatedly solve the associated eigenvalue problem with a large number of degrees of freedom for the finite element mesh of a vehicle in a crashworthiness analysis. Therefore, approximate solutions, mainly based on the analysis of the individual finite element, must be used for a conservative estimate of an efficient time step.

A conservative estimate of the critical step length for the spatially discretized equations of motion for the complete structure is computed from the largest value $\omega_{\max }$ of the set of maximum eigenfrequencies of all individual finite elements $e: \omega_{\max }^{\text {system }} \leq \max _{e}\left(\omega_{\max }^{e}\right)$, where $\omega_{\max }^{e}$ is the maximum frequency of the $e$-th element subjected to zero traction boundary conditions [Irons 1970; Hughes et al. 1979]. The maximum eigenvalue of solid elements is often approximated by the bar wave velocity $c$ and the smallest distance $\Delta l$ of two arbitrary nodes within the element, leading to the critical time step $\Delta t_{\text {crit }}=\Delta l / c$. If only one solid element over the thickness $d_{k}$ is used for the spatial modeling of thin adhesive layers, the smallest distance $\Delta l$ between adjacent nodes is equal to $d_{k}$. The criterion above leads to an inefficiently small critical time step, since the length of any edge in any of the finite elements must currently be at least $5 \mathrm{~mm}$ for the crash analysis of complete vehicle bodies to guarantee a reasonable run time in practice. Therefore, we resort to another estimate for the critical size of the time step.

The distributed springs, symbolizing the stiffness, provided by an eight node interface element connect the masses of the top and bottom planes in Figure 3, left.

Both planes may consist of shell elements, describing the adjoining sheet metal or the surfaces of solid elements, used for the modeling of more bulky structural parts. The masses of both surfaces mainly 

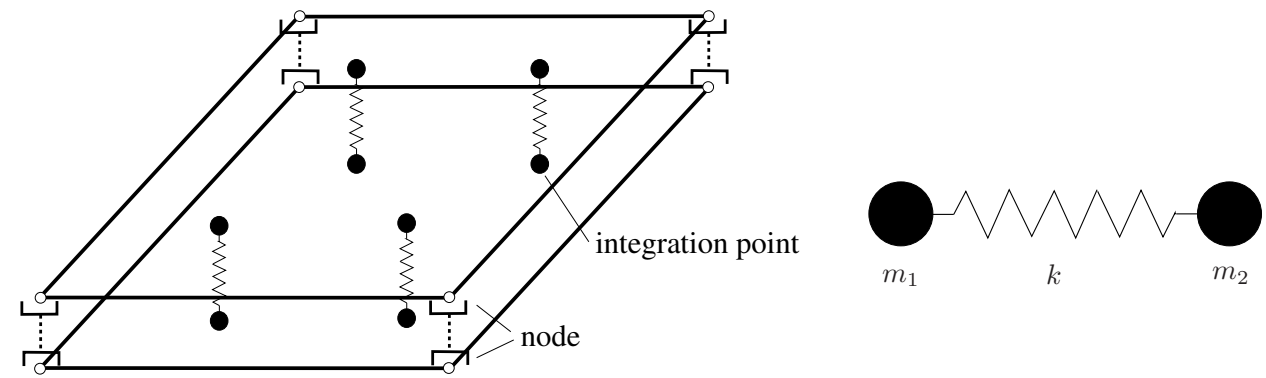

Figure 3. Left: interface element symbolized by distributed springs. Right: spring-mass system.

come from the bonded steel components and, to a small extent, from the adhesive layer. Figure 3, right, shows a node with mass $m_{1}$ in the top plane and a neighbouring node with mass $m_{2}$ in the bottom surface, connected by a discrete spring with stiffness $k$, which is computed by numerical quadrature at the integration points of the interface element. The parameter $k$ equals the product of the shear or normal stiffness times a quarter of the element area in the case of an eight node interface element. The critical time step for the spring-mass system is given by:

$$
\Delta t_{\text {crit }}=2 \sqrt{\frac{m_{1} m_{2}}{m_{1}+m_{2}} \frac{1}{k}} .
$$

Note from this equation that the thickness $d_{k}$ of the adhesive layer does not enter the estimate of the critical time step for the interface element. It may be shown by numerical investigation that the critical time step of the solid elements for the steel parts is not further limited by this estimate for the interface elements.

\section{Numerical examples for delamination analysis}

The interface elements, along with the traction-separation equations of mixed-mode fracture and elastoplasticity, were coded into the finite element program FEAP [FEAP 2002] and the commercial code LSDYNA [DYNA 1998; DYNA 2006] as user defined material models. The performance of the different approaches are demonstrated by means of the double cantilever beam (DCB) and fixed ratio mixed-mode (FRMM) tests for delamination, all run with FEAP. The values of the elastic interface stiffness terms $K_{n}$ and $K_{t}$ serve more or less as penalty parameters in the case of delamination analysis and are kept in a reasonable range, where the stiffness does not obstruct the condition number of the stiffness matrix in implicit analysis [Fiolka and Matzenmiller 2007] or the time step of the explicit runs.

4A. DCB test. The double cantilever beam (DCB) test, shown schematically in Figure 4, is a widely used interlaminar fracture test of fiber-reinforced structures to analyze crack growth in mode I. The material parameters $E_{11}, E_{22}, G_{12}, G_{13}$, and $v_{12}$ of the orthotropic elasticity model for the DCB specimen, made of fiber-reinforced composite material, are given in Table 1 together with the material constants for mode I of the Hillerborg fracture model.

For the analysis of the delamination test, two kinds of elements are used: the three-dimensional interface element (see Section 2A) and a locking-free solid-shell element [Fiolka and Matzenmiller 2007]. 

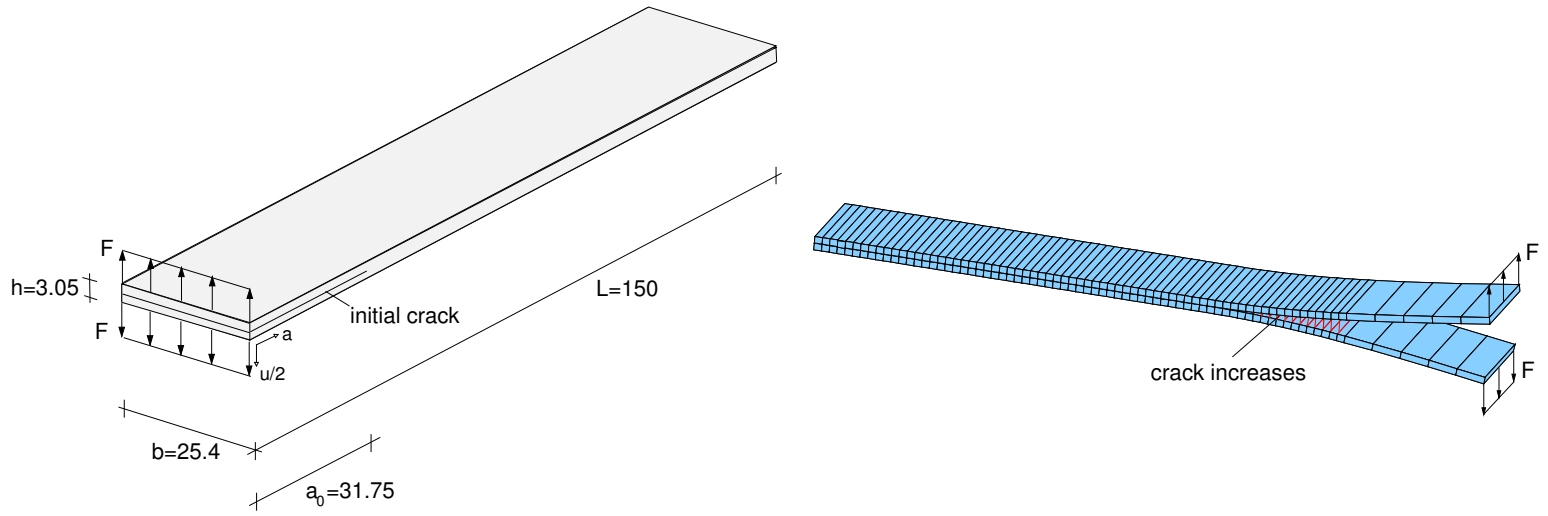

Figure 4. DCB test setup and finite element model.

The convergence study reveals that 140 interface elements along the length of the uncracked specimen of $118.25 \mathrm{~mm}$ are sufficient for the accurate resolution of the load-deflection diagram. A total of 290 solid-shell elements are taken for the double cantilever [Fiolka 2007].

Figure 5, left, displays the experimental data from [Aliyu and Daniel 1985] and the analytical solution from [Mi et al. 1998] together with the finite element simulation. The numerical and the experimental results are identical until the load peak is reached, where the crack begins to increase. During the delamination process, the forces in the numerical and the analytical solutions match very well. Further finite element simulations have shown that the shape of the traction-separation equation, here taken as bilinear or trilinear as in the Tvergaard-Hutchinson model, has only a small influence on the forcedisplacement curve.

The interface stiffness parameters $K_{n}$ and $K_{t}$ are chosen to be sufficiently large enough in Table 1, since practically the same result is obtained as in Figure 5, left, for the numerical case, if $K_{n}$ and $K_{t}$ are reduced to $12000 \mathrm{~N} / \mathrm{mm}^{3}$ or increased to $30000 \mathrm{~N} / \mathrm{mm}^{3}$; see Figure 5, right.
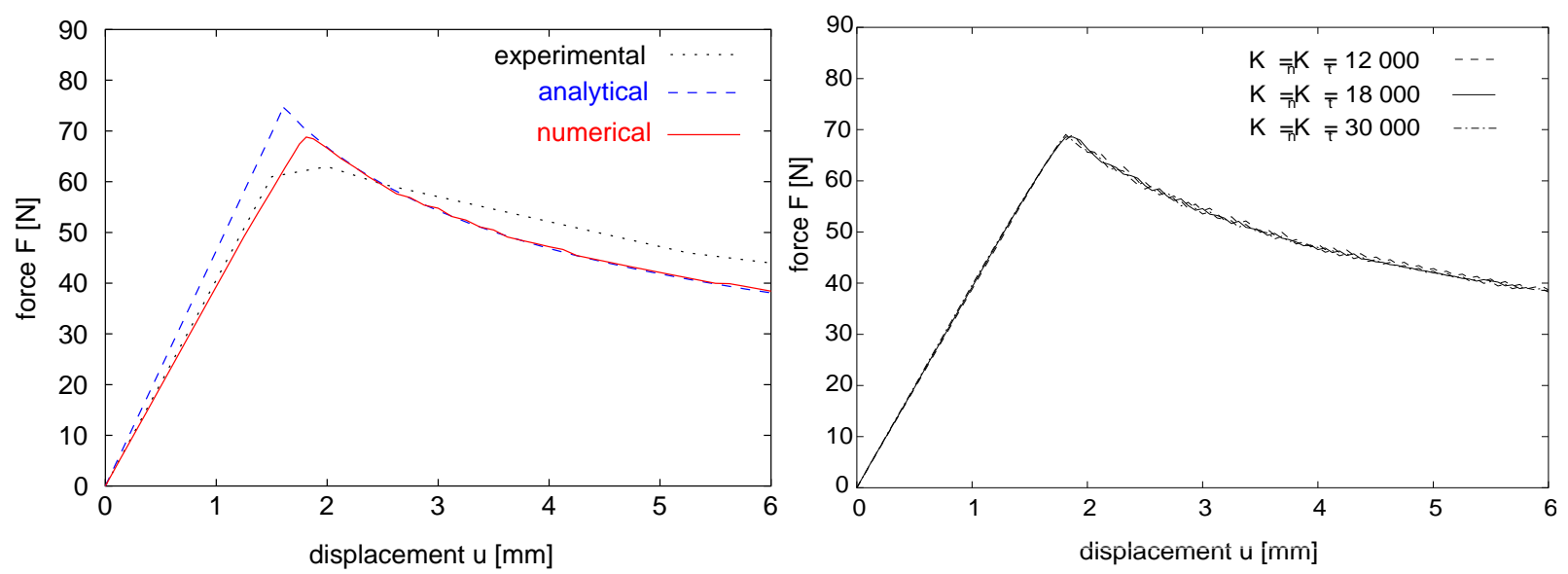

Figure 5. Left: Experimental data and simulation results of the mixed-mode fracture model for the DCB test. Right: Results for various interface stiffness values $K_{n}$ and $K_{t}$ of the mixed-mode fracture model for the DCB test from [Fiolka 2007, page 115]. 


\begin{tabular}{|lll|}
\hline Elasticity moduli & $E_{11}=138000 \mathrm{~N} / \mathrm{mm}^{2}$ & $E_{22}=8960 \mathrm{~N} / \mathrm{mm}^{2}$ \\
Shear moduli & $G_{12}=7100 \mathrm{~N} / \mathrm{mm}^{2}$ & $G_{23}=3446 \mathrm{~N} / \mathrm{mm}^{2}$ \\
Poisson's ratio & $v_{12}=0.3$ & \\
Elastic interface stiffness & $K_{n}=18000 \mathrm{~N} / \mathrm{mm}^{3}$ & $K_{t}=18000 \mathrm{~N} / \mathrm{mm}^{3}$ \\
Maximal interface stress & $t_{3}^{\max }=51.7 \mathrm{~N} / \mathrm{mm}^{2}$ & \\
Energy release rate & $\varphi_{\text {Ic }}=222 \mathrm{Nm} / \mathrm{m}^{2}$ & \\
\hline
\end{tabular}

Table 1. Material parameters for orthotropic elasticity model of composite and bilinear interface model of DCB test from [Teßmer 2000; Fiolka 2007].

\begin{tabular}{|lll|}
\hline Elasticity moduli & $E_{11}=130000 \mathrm{~N} / \mathrm{mm}^{2}$ & $E_{22}=8000 \mathrm{~N} / \mathrm{mm}^{2}$ \\
Shear moduli & $G_{12}=6000 \mathrm{~N} / \mathrm{mm}^{2}$ & $G_{23}=3000 \mathrm{~N} / \mathrm{mm}^{2}$ \\
Poisson's ratio & $v_{12}=0.27$ & \\
Elastic interface stiffness & $K_{n}=100000 \mathrm{~N} / \mathrm{mm}^{3}$ & $K_{t}=100000 \mathrm{~N} / \mathrm{mm}^{3}$ \\
Maximal interface stress & $t_{1}^{\max }=48.0 \mathrm{~N} / \mathrm{mm}^{2}$ & $t_{3}^{\max }=48.0 \mathrm{~N} / \mathrm{mm}^{2}$ \\
Energy release rates & $\varphi_{\text {Ic }}=257 \mathrm{Nm} / \mathrm{m}^{2}$ & $\varphi_{\text {IIc }}=856 \mathrm{Nm} / \mathrm{m}^{2}$ \\
Interaction parameter & $n=2$ & \\
\hline
\end{tabular}

Table 2. Material parameters of orthotropic elasticity model for composite layer and interface model for FRMM test.

4B. FRMM test. Among the mixed-mode bending tests, the FRMM test in Figure 6 is a common benchmark for the investigation of interlaminar fracture and for the determination of the mixed-mode properties for the delamination process in fiber-reinforced composite structures. The layered composite is notched at the free end over a length of $a_{0}=45 \mathrm{~mm}$ and clamped at the other end. The material parameters of the FRMM specimen, made of carbon fiber-reinforced epoxy resin [Chen et al. 1999], are given in Table 2. The parameters for the elastic interface stiffness are chosen in accordance with the earlier considerations. A transverse load is applied at the free edge of the upper layer. The length of the finite elements is chosen as $0.87 \mathrm{~mm}$ in the direction of the crack growth after a convergence study of the mesh size has been undertaken on the experience of the DCB test. Hence, 148 volume-shell elements and 69 interface elements are used in total.

The simulation results are compared to the experimental data and the analytical solution in Figure 7, left. The Hillerborg mixed-mode model approximates the experimental load-displacement curve fairly well for an interaction parameter of $n=2$ in (2-4). However, the Tvergaard-Hutchinson model
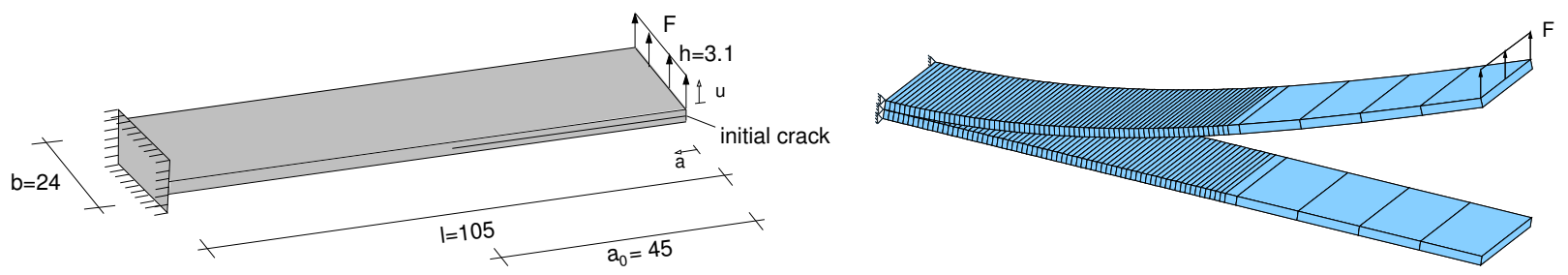

Figure 6. FRMM test setup. 
underestimates the experimental load-displacement curve, because the critical energy release rate $\mathscr{G}_{c}$ in (2-8) takes only the mode I part into account. Again, it can be shown that the shape of the graph from the traction-separation equation has only a minor effect on the load-displacement relation - see Figure 7 , right, where the force-displacement curve with $\lambda_{1}=\lambda_{2}=0.1$ (the bilinear shape) is compared to the one with $\lambda_{1}=0.2$ and $\lambda_{2}=0.6$ (the trilinear shape in Figure 2).

\section{Failure analysis of adhesive bonds}

The proposed interface models are used for the simulation of the mechanical behavior of adhesively bonded joints until failure of the adhesive layer occurs. Therefore, the bonded tube test, the peel test, and the KS-II test are simulated with LS-DYNA and explicit time integration. The numerical results are compared to the experimental data. The thickness of the adhesive layers is between 0.25 and $0.30 \mathrm{~mm}$ for all specimens.

5A. Experimental results for toughened adhesives. Structural adhesives are crash-resistant, toughened plastic polymers, nowadays used in bonding applications. The material behavior of crash-resistant adhesives such as Betamate 1496, SikaPower 490-6, EP 12, or Terokal 5070 was comprehensively examined in an earlier research project [Schlimmer et al. 2002]. A typical characteristic behavior of toughened adhesives is plastic flow under shear as well as hydrostatic loading, as can be measured in tension and torsion tests of adhesively bonded tubes. The constitutive response in shear of a crash-resistant adhesive under slow loading, complete unloading, and reloading was investigated in [Schlimmer 2003] with a shear strain rate of $\dot{\gamma}_{x y}=2 \cdot 10^{-3} \mathrm{~s}^{-1}$. The shear stress-shear strain from the test is shown in Figure 8 , where permanent strains $\gamma_{x y, b l}$ remain in the specimen, if the external load exceeded the yield limit before unloading took place. The hysteresis loops due to cyclic loading are neglected in the elastoplastic approach and the linear elastic response with the shear modulus $G_{s}$ is fitted to the unloading/reloading paths.
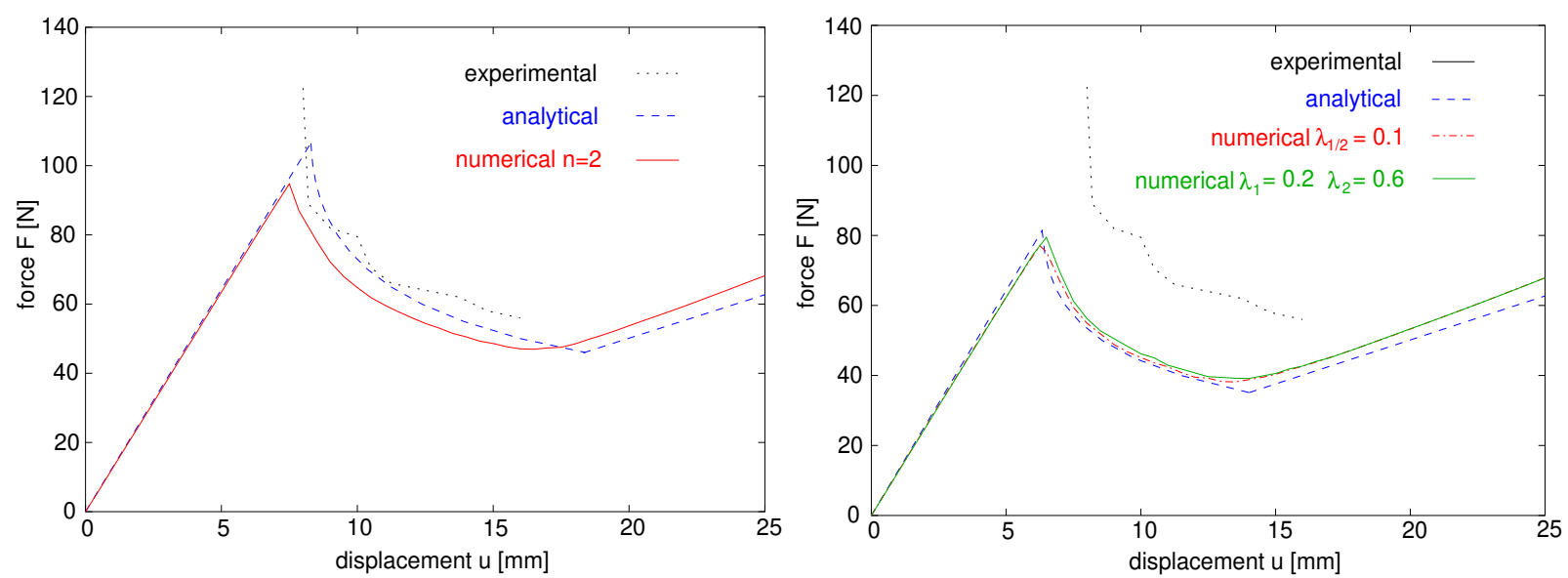

Figure 7. Left: Experimental data and simulation results of the Hillerborg mixed-mode interface model for FRMM test. Right: Experimental data and simulation results of the Tvergaard-Hutchinson mixed-mode interface model for the DCB test. 


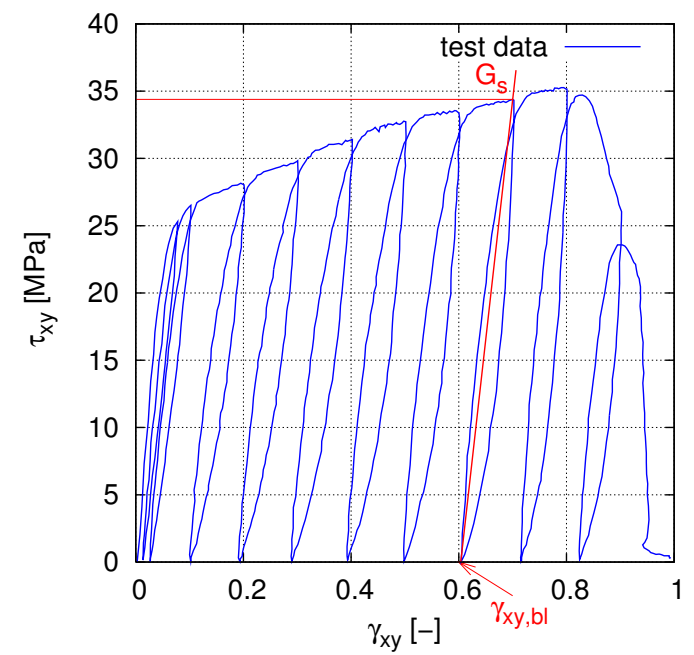

Figure 8. Stress-strain diagram of crash-resistant adhesive EP 12 under cyclic loading from [Schlimmer 2003].
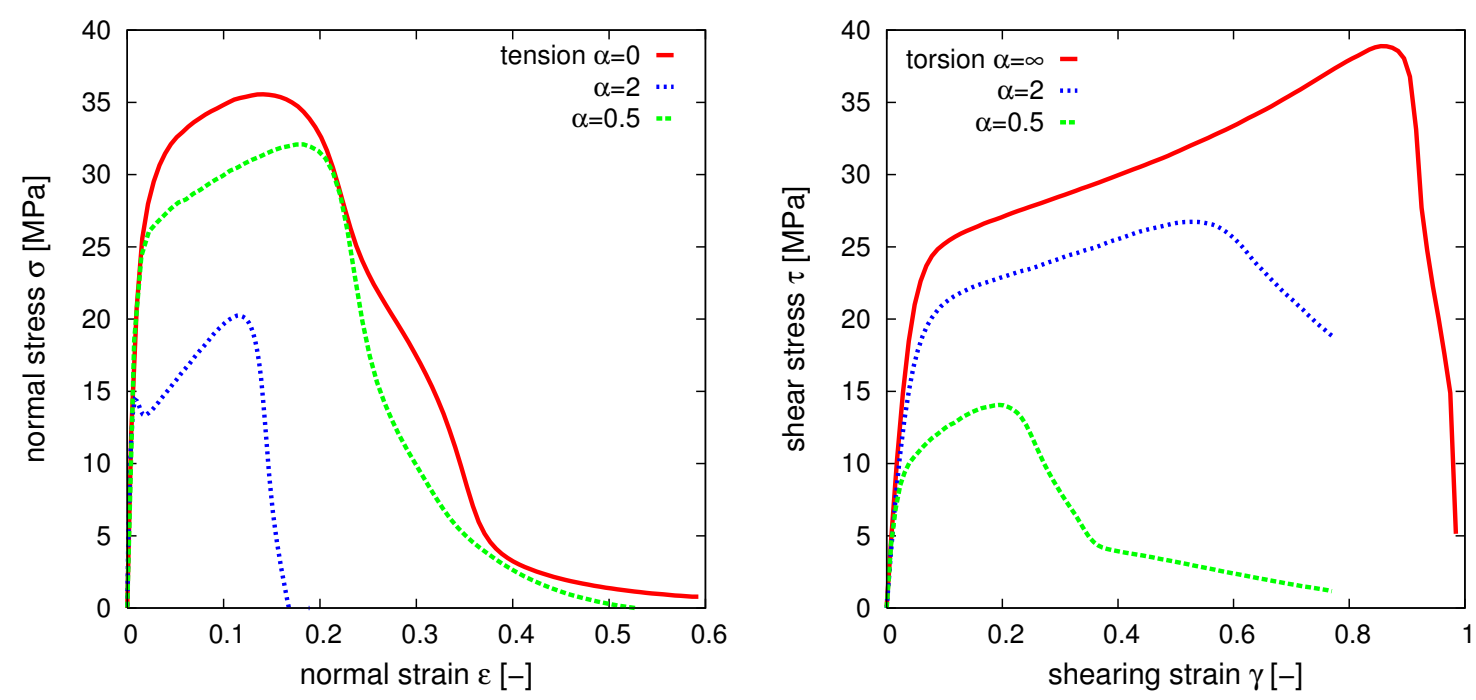

Figure 9. Experimental results of pure tension, pure torsion, and combined tensiontorsion tests of adhesively bonded tubes from [Schlimmer 2003].

The material behavior in Figure 9 is typical for an adhesive layer between two bonded steel tubes under uniaxial tension and torsion loading. The experimental data for the stress-strain diagrams have been provided by Schlimmer [2003]. The combined tension-torsion tests are characterized by the ratio $\alpha=\gamma /(2 \epsilon)$ of normal to shear strains $\epsilon$ and $\gamma$. In Figure 9 the results of pure tension $(\alpha=\infty)$ and torsion $(\alpha=0)$ tests and two combined tension-torsion experiments with $\alpha=0.5$ and $\alpha=2.0$ are shown.

The rate dependency of the yield stress or stress at failure is investigated by means of tension tests at butt-jointed specimens and of shear tests at thick shear lap specimens [Schlimmer et al. 2008]. The 


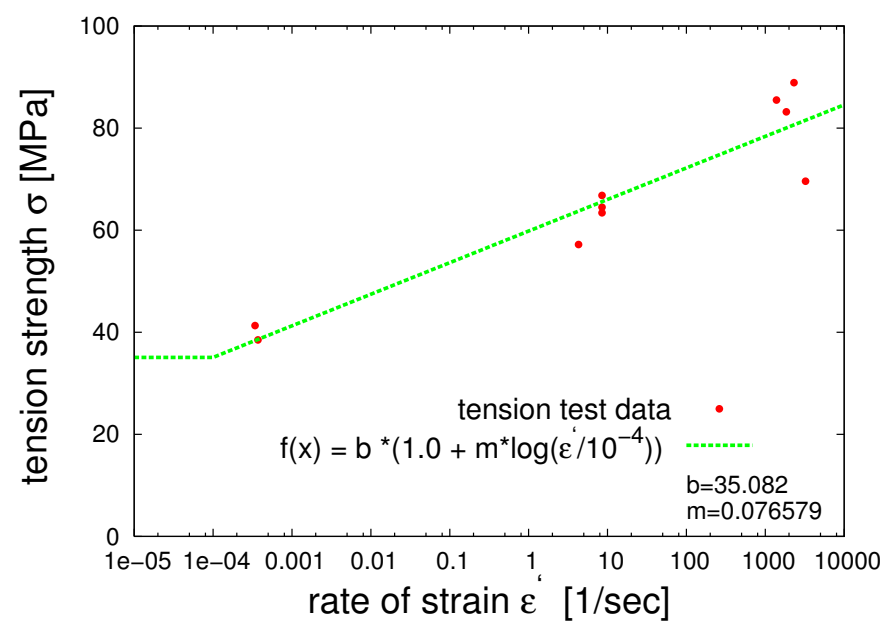

Figure 10. Experimental data for rate-dependent tensile strength of adhesively bonded joints and least square fit of model response for butt-jointed specimen from [Jendrny 2005; Schlimmer et al. 2008].

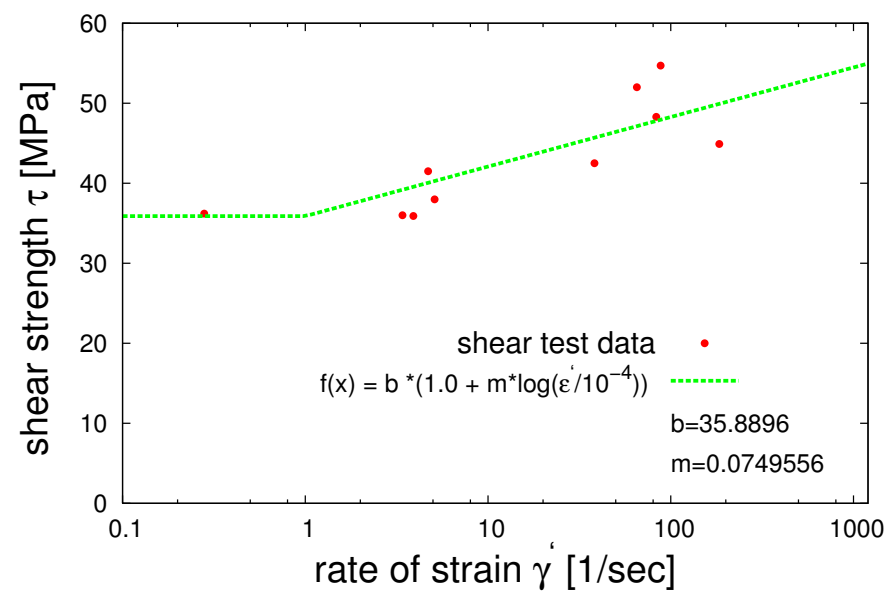

Figure 11. Experimental data for rate-dependent shear strength of adhesively bonded joints and least square fit of model response for thick shear lap specimen from [Jendrny 2005; Schlimmer et al. 2008].

results are summarized in Figures 10 and 11 together with the least square fit to the data of the functions in (2-5).

5B. Numerical analysis of bonded tubes. The bonded tube test above consists of two hollow metal cylinders, joined at the cross section by an adhesive layer of Betamate $1496 \mathrm{~V}$. An axial force or a torque is applied at the upper end of the structure, while the far end of the lower cylinder is kept fixed (see Figure 12). The parameters of the elastic-plastic interface model, discussed above, are determined by fitting the model response to the data [Schlimmer et al. 2002] from the pure tension and pure torsion tests of the bonded tubes. These are given in Table 3. The elastic interface stiffness parameters $K_{n}$ and $K_{t}$ 


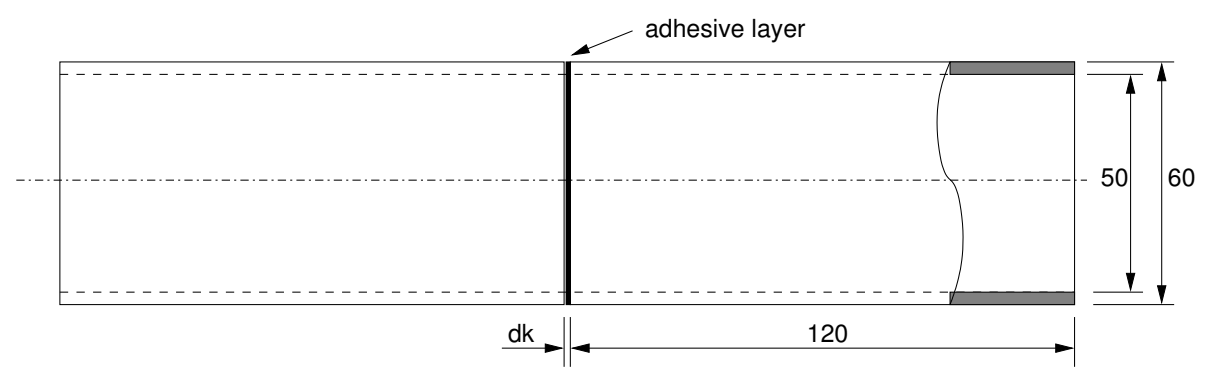

Figure 12. Bonded tubes with geometrical data.

coincide with the measured stiffness values for the adhesive layer with thickness of $0.3 \mathrm{~mm}$. Dividing the elasticity modulus and shear modulus of the adhesive layer by the thickness delivers the values chosen for $K_{n}$ and $K_{t}$ in Table 3. The combined tension-torsion tests for $\alpha=0.5$ and $\alpha=2.0$ are used as validation examples. The adhesive layer is meshed by 28 interface elements in the circumferential direction of the tube. Figure 13 shows the experimental data from [Schlimmer et al. 2002] and the simulation results of the stress-strain curves from the elastoplastic interface model in Section 2D.

The results of the finite element simulation agree sufficiently with the experimental data in the pure tension and pure torsion tests, which are performed for the identification of the constitutive parameters. The stress-strain curves in Figure 13 show that the different yield limits in the normal and tangential directions correspond to the experimental data. The hardening of the adhesive layer is approximated fairly well by the linear course of the graph from the model, whereas the displacement jump at the failure of the adhesive bond is not so well represented in the load cases of combined tension and torsion.

Although the model is very flexible, allowing independent approximations of yielding due to tension and shear, its capability to describe the postcritical behavior is very limited. It does not permit representing the initiation of softening and the state of failure separately. There is only one variable $\beta$ (see (2-14)), which may be identified such that either the initiation of softening at $\bar{\gamma}_{\text {crit }}$ or the failure at $\bar{\gamma}_{\text {fail }}$ takes place in tension and shear at the same time in both modes of plastic flow. In this paper the determination of the parameter $\beta$ is a compromise between the onset of softening and the occurrence of complete failure. In conclusion, the model has only two parameters $\beta$ and $\bar{\gamma}_{\text {crit }}$ (see Table 3) to describe the points of maximum stress at the critical discontinuity and zero stress at failure $\bar{\gamma}_{\text {fail }}$ for both modes of yielding. The combined tension-torsion tests for $\alpha=0.5$ and $\alpha=2.0$ serve as examples for

\begin{tabular}{|lll|}
\hline Elastic interface stiffness & $K_{n}=6500 \mathrm{~N} / \mathrm{mm}^{3}$ & $K_{t}=2500 \mathrm{~N} / \mathrm{mm}^{3}$ \\
Yield limits & $Y_{0}^{(1)}=30.0 \mathrm{MPa}$ & $Y_{0}^{(2)}=26.0 \mathrm{MPa}$ \\
Hardening modulus & $H_{\text {hard }}^{(1)}=210 \mathrm{MPa} / \mathrm{mm}$ & $H_{\text {hard }}^{(2)}=450 \mathrm{MPa} / \mathrm{mm}$ \\
Softening modulus & $H_{\text {soft }}^{(1)}=580 \mathrm{MPa} / \mathrm{mm}$ & $H_{\text {soft }}^{(2)}=5000 \mathrm{MPa} / \mathrm{mm}$ \\
Coulomb friction parameter & $\mu=0.55$ & \\
Interaction parameter & $\beta=0.039$ & \\
Critical displacement jump & $\bar{\gamma}_{\text {crit }}=0.035 \mathrm{~mm}$ & \\
\hline
\end{tabular}

Table 3. Material parameters of elastic-plastic interface model. 

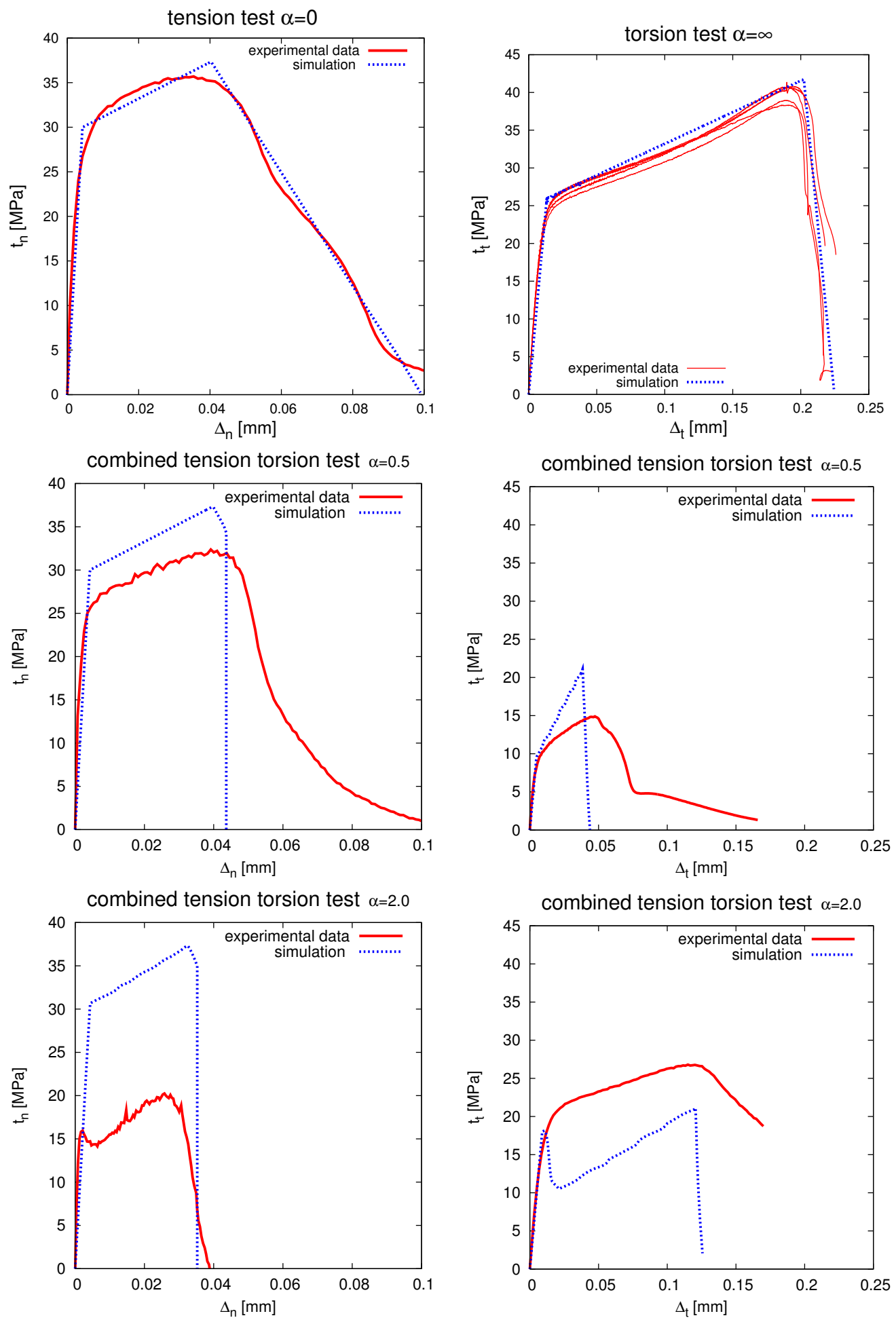

Figure 13. Comparison between experimental data and simulation results of elasticplastic interface model for tension, torsion, and combined loading tests of bonded tubes. 

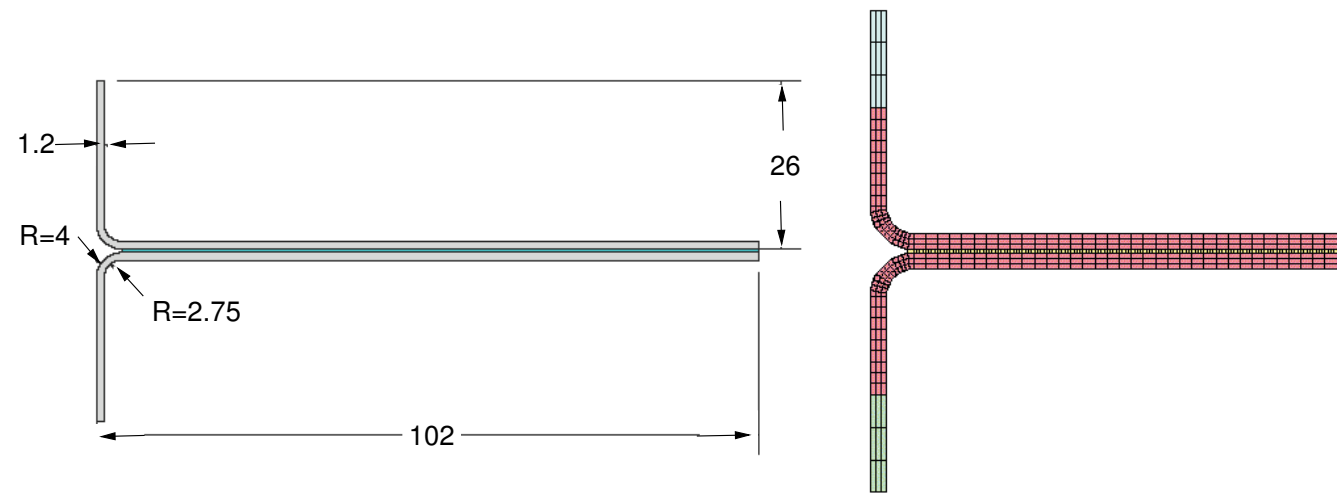

Figure 14. Geometry of peel test specimen and FE mesh of front part.

the validation of the model's hypotheses in describing the plastic flow in nonuniaxial situations. The prediction of the mechanical behavior from the simulation using LS-DYNA for these combined loading tests is not satisfactory for the special adhesive Betamate 1496. The mode interaction behavior should be improved for this adhesive, as should the simple assumption for the flow vector $\boldsymbol{m}^{(2)}=\boldsymbol{t}_{t}$ in mode II (see (2-12)).

5C. Numerical analysis of peel test. The first series of specimens with inhomogeneous stress distributions and fracture to be examined for adhesive joints is the peel test. It resembles the DCB specimen (see Figure 14), where two metal sheets with width $b=25 \mathrm{~mm}$ are glued together with the crash resistant adhesive Betamate $1496 \mathrm{~V}$ and torn apart by forces at the ends normal to the bonding. However, the metal sheets deform plastically during the peeling process, whereas in the DCB test the laminae bend only within the elastic range.

The peel test is analyzed with the mixed-mode fracture model and the elastic-plastic interface approach for the adhesive. Rate-independent material models are used for the adhesive and conventional PrandtlReuss plasticity theory of the von Mises type for the steel of the sheet metal. The material constants from Table 3 are taken for the plasticity model of the adhesive and from Table 4 for the isotropic, ideal plastic description of the adherends and the mixed-mode fracture model. The constitutive parameters of the latter in Table 4 are determined on the basis of fracture tests for modes I and II by Brede and Hesebeck [2005].

\begin{tabular}{|lll|}
\hline Elasticity modulus steel & $E=209000 \mathrm{~N} / \mathrm{mm}^{2}$ \\
Poisson's ratio steel & $v=0.3$ \\
Yield limit steel & $Y_{0}=350 \mathrm{~N} / \mathrm{mm}^{2}$ & \\
Elastic interface stiffness & $K_{n}=6500 \mathrm{MPa} / \mathrm{mm}, \quad K_{t}=6500 \mathrm{MPa} / \mathrm{mm}$ \\
Maximal interface stress & $t_{n}^{\max }=20.0 \mathrm{MPa}$, & $t_{t}^{\max }=39.5 \mathrm{MPa}$ \\
Energy release rate & $\mathscr{G}_{\text {Ic }}=5400 \mathrm{Nm} / \mathrm{m}^{2}$ & $\mathscr{G}_{\mathrm{IIc}}=\mathscr{G}_{\mathrm{IIIc}}=23000 \mathrm{Nm} / \mathrm{m}^{2}$ \\
Interaction parameter & $n=2$ & \\
\hline
\end{tabular}

Table 4. Material parameters of steel sheets and mixed-mode cohesive zone model from [Brede and Hesebeck 2005]. 


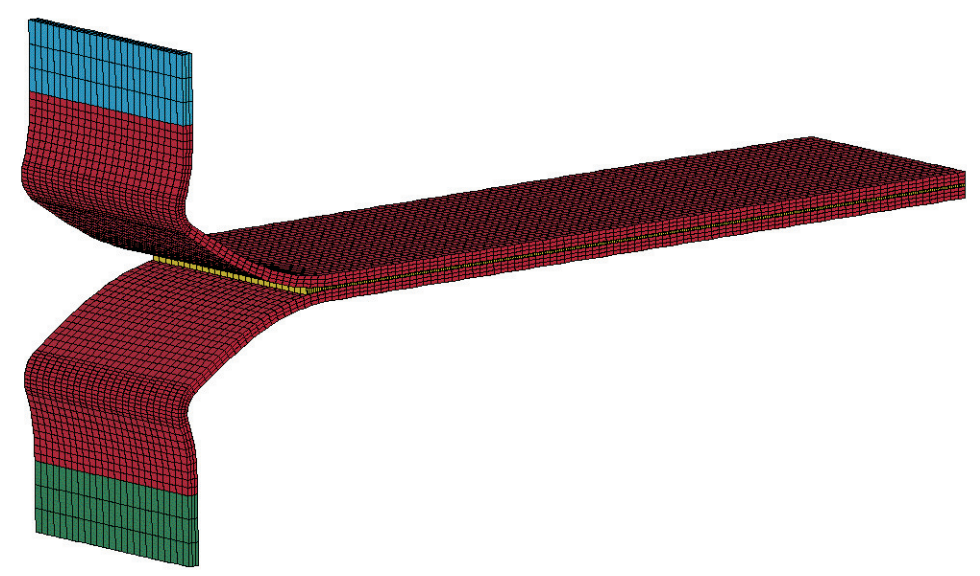

Figure 15. FE model of deformed shape of peel test specimen.

The FE model of the peel test consists of 473 interface elements along the length and 25 in the cross direction of the adhesive layer. Three linear solid elements are taken through the thickness of each steel sheet and 137 in the length direction. With an element size of about $1.1 \mathrm{~mm}$ for the hexahedron of the steel and $0.275 \mathrm{~mm}$ for the interface elements of the adhesive, the finite element mesh may be considered as converged in practice. The boundary value problem is solved with the commercial code LS-DYNA [DYNA 2006], extended by the user interface element with the constitutive models above, and explicit time integration. The test is simulated with a constant velocity boundary condition of $140 \mathrm{~mm} / \mathrm{s}$ at the upper end. The deformed specimen is shown in Figure 15.

The comparison of the simulation results with the experimental data from [Schlimmer et al. 2008] is presented in Figures 16 and 17 by means of the load-displacement curves. The typical features of these are the peak force at the beginning, when the crack starts to open, and the decrease of the resultant force value during the advancing peel process. The simulations with the mixed-mode model (Figure 16) and the elastic-plastic interface approach (Figure 17) lead to different peak values of the force in the cases with data from [Schlimmer 2003; Brede and Hesebeck 2005]. The mixed-mode model with these data clearly overestimates the maximum load carrying capacity of the specimen; obviously, the force during the peeling process is significantly greater than that of the corresponding experimental data (Figure 16).

The excessively high load carrying capacity in the simulation with the mixed-mode model, shown in blue (upper dotted curve) in Figure 16, is mainly due to the loss of adhesion bonding at the surface of the adherends in the experiments as outlined in [Schlimmer et al. 2008, chapter 3.1.7]. However, the material data for the energy release rates in Table 4 are determined in [Brede and Hesebeck 2005] for cohesive fracture at a much higher load carrying capacity. In summary, they may be too large, since the area under the experimentally measured diagrams of the stress versus crack opening displacement is, according to the tests in [Schlimmer 2003], about $3240 \mathrm{Nm} / \mathrm{m}^{2}$ in the case of pure tension, $\alpha=0$ in Figure 13a, and $12900 \mathrm{Nm} / \mathrm{m}^{2}$ in the case of torsion, $\alpha=\infty$ for pure shearing in Figure 13b. If these values are taken for the critical energy release rates $\varphi_{\text {Ic }}$ and $\varphi_{\text {IIc }}$ with the maximal interface stresses adjusted to $t_{n}^{\max }=35.0 \mathrm{MPa}$ and $t_{t}^{\max }=39.0 \mathrm{MPa}$, the red (solid) curves in Figure 16 follow from the simulation with the mixed-mode fracture model [Schlimmer et al. 2002; Schlimmer 2003]. In the third run, the energy release rates are lowered to $\mathscr{G}_{\text {Ic }}=1300 \mathrm{Nm} / \mathrm{m}^{2}$ and $\mathscr{G}_{\text {IIc }}=10000 \mathrm{Nm} / \mathrm{m}^{2}$ as inversely identified in 

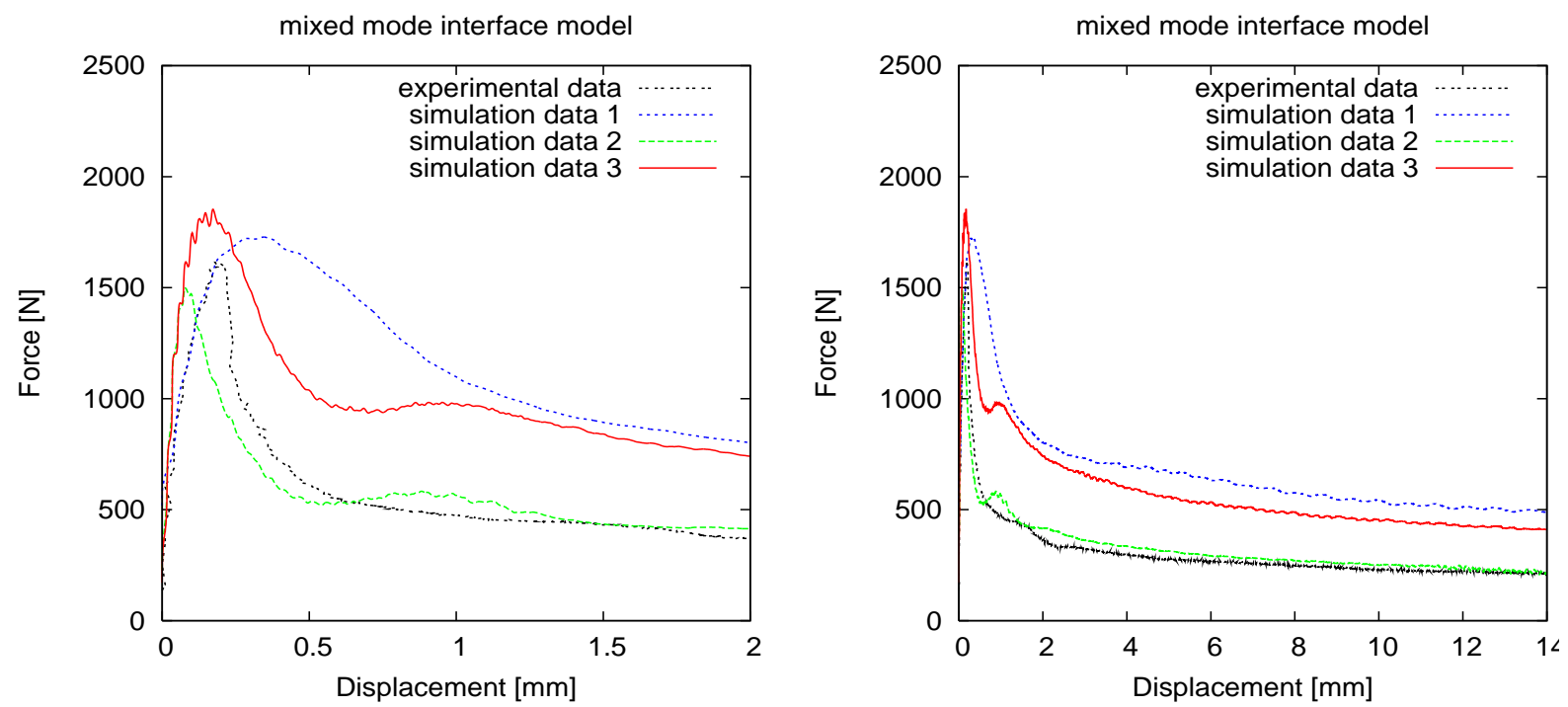

Figure 16. Results of the peel test computed with mixed-mode interface model and compared to experimental data. Simulation data \#1 is from [Brede and Hesebeck 2005], \#2 from [Schlimmer et al. 2008], and \#3 from [Schlimmer 2003].

[Schlimmer et al. 2008], where the maximal stresses are changed slightly to $t_{n}^{\max }=43.0 \mathrm{MPa}$ and $t_{t}^{\max }=$ 39.0 MPa. Shown in green (light-colored dashed graph), this solution approximates the test data best.

The data in Figure 17 suggest that the elastic-plastic interface model approximates the maximum resultant force of the experiment very well, but the peak is slightly shifted towards the left. The forces of the interface model during the peeling process coincide with the experimental data (see Figure 17).
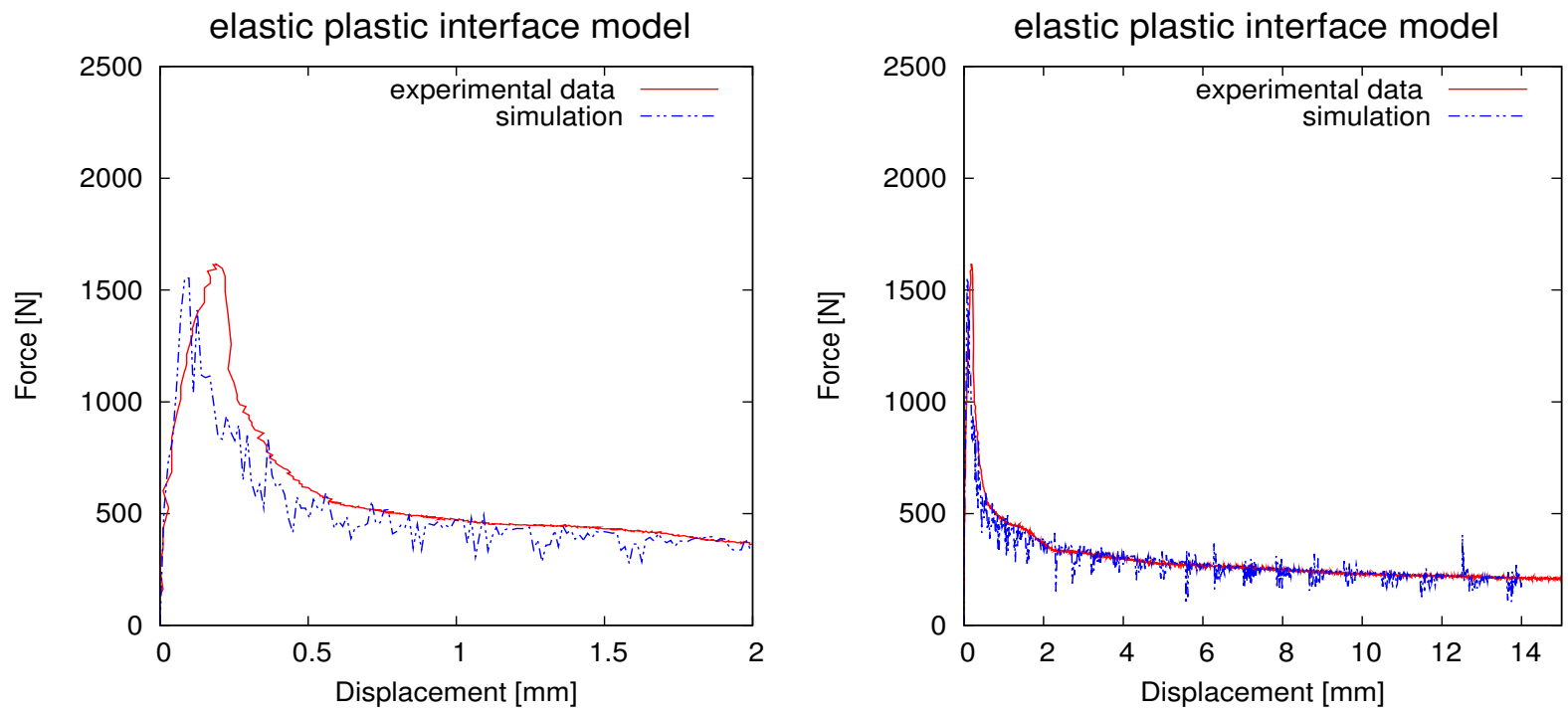

Figure 17. Comparison of experimental data for peel test with the response of the elastic-plastic interface model. 


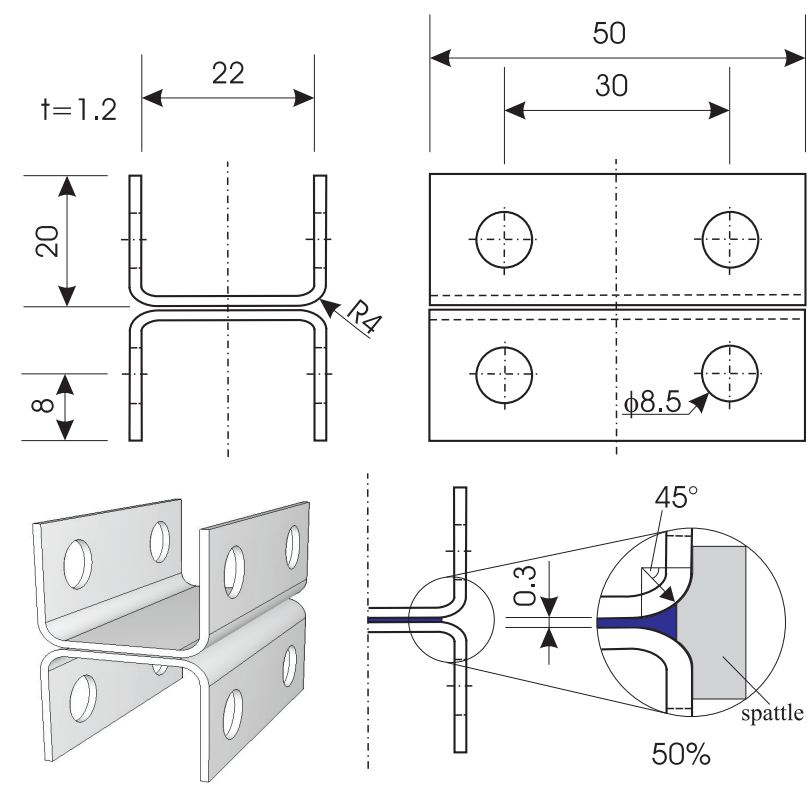

Figure 18. Geometry of KS-II test specimen, and underfilling (lower right).

5D. KS-II test. Hahn et al. [1999] developed an experimental setup to investigate the mechanical behavior of adhesively bonded joints under tensile and shear loading (see Figures 18 and 19). The purpose of the test is to characterize and evaluate the behavior of bonding techniques under different mechanical stress conditions. Two U-shaped steel components are joined together with an adhesive similar to a flange in an automotive application (see Figure 18). The dimensions of the adhesive layer are $23 \mathrm{~mm}$ by $16 \mathrm{~mm}$ with a thickness of $0.3 \mathrm{~mm}$. The underfilling of $50 \%$ at the edge of the adhesive layer is shown in Figure 18, right.

The test specimen can be pulled apart with different clamping devices under various angles of loading with respect to the normal on the adhesive layer (see Figure 19). Four different load angles are chosen

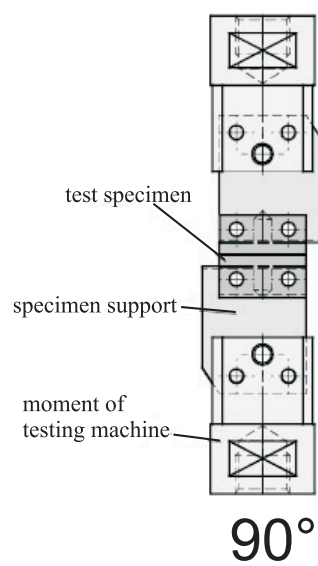

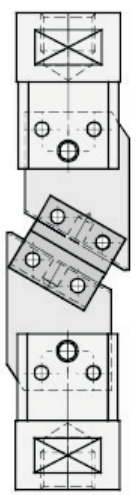

$60^{\circ}$

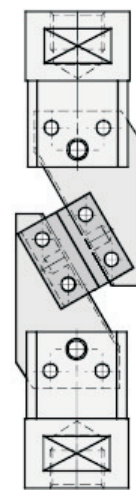

$30^{\circ}$

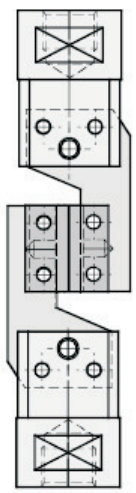

$0^{\circ}$

Figure 19. Test control unit and load cases. 

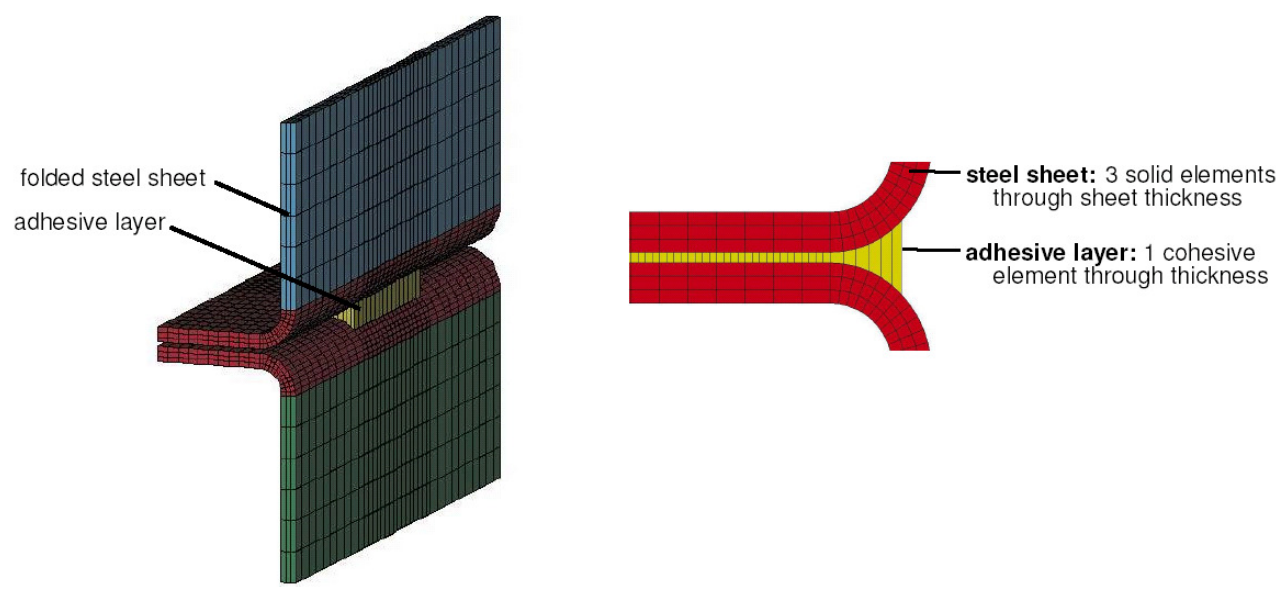

Figure 20. Finite element idealization of symmetric half model.

with $0^{\circ}$ for pure shear loading, $90^{\circ}$ for normal loading, and the two intermediate angles $30^{\circ}$ and $60^{\circ}$ for combined tension and shear stressing. The loading is applied in terms of prescribed nodal velocities on the far ends of the U-shaped profiles, which are mounted on steel support jaws, treated as rigid in the FE model. In order to investigate the influence of the rate-dependency, analysis and experimental testing have been performed for loading velocities of $v=1.0 \mathrm{~m} / \mathrm{s}$, in addition to the quasistatic one with $v=10 \mathrm{~mm} / \mathrm{min}$. The displacement is measured $15 \mathrm{~mm}$ below the upper and lower edges of the specimen on the line of symmetry.

In the numerical analysis, only the symmetrical half of the specimen is analyzed, as shown in Figure 20, left. Since the validation of the substitute element for the bonding was the primary intent, both the adhesive layer and the adherent steel parts are meshed fairly finely with the interface elements in the region of the bonding. The adhesive bond is meshed with 16 interface elements lengthwise and 46 interface elements crosswise. However, outside of this area the steel parts in the clamping devices are modeled as rigid bodies, where the loading in terms of prescribed nodal velocities is applied. Special attention has to be given to the filling at the outer edge of the adhesive layer around the corner from the steel parts (see the right side of Figure 20). Due to the increased thickness, the strains in the filling are smaller and, thus, local failure takes place later.

Each load case has been investigated with both constitutive models mentioned above for the adhesive. The material parameters of the mixed-mode fracture model are determined on the basis of fracture tests (see Table 4 for the mechanical properties). The material parameters for the elastic-plastic model in Table 3 are identified from the data from experimental tests at bonded tubes with a fairly homogeneous state of stress in the adhesive layer under tension and torsion. These are used in the analysis of the KS-II test.

The results of the analysis are plotted as the total internal force in the load direction versus the local displacement in Figures 21-24 and compared to the data measured in the experiments [Schlimmer et al. 2008]. The local displacements in the experiment are computed as the difference of the displacement vectors for two marked points on the clamped legs of the upper and lower U-shaped steel parts. In the finite element analysis, the local displacement is defined as the discontinuity between the displacements of the rigid bodies for parts of the upper and lower steel components. The force in the load direction on the ordinate of the diagrams is calculated in the theoretical investigation from the stresses in the adhesive 
layer by summing them over the entire area. It is generally impossible to measure with a device the force in the adhesive layer without influencing its properties with embedded particles. Therefore, the force cannot be recorded close to the glued interface in the current test setup and a measurement cell is put into the top of the upper clamping device. Due to the inertial effects of the mass for the steel parts between the adhesive layer and the measurement cell, the measured forces differ from the total internal force, transferred through the adhesive joint between the lower and upper steel components. It is difficult to estimate the deviation of the internal force in the measurement device from the resultant on the cut through the adhesive layer. Despite the unknown error between the measured force in the clamping device and the stress resultant on the adhesive layer we compare the measured force from the test to the calculated resultant in the joint and plot both quantities over the local displacements in Figures 21-24.
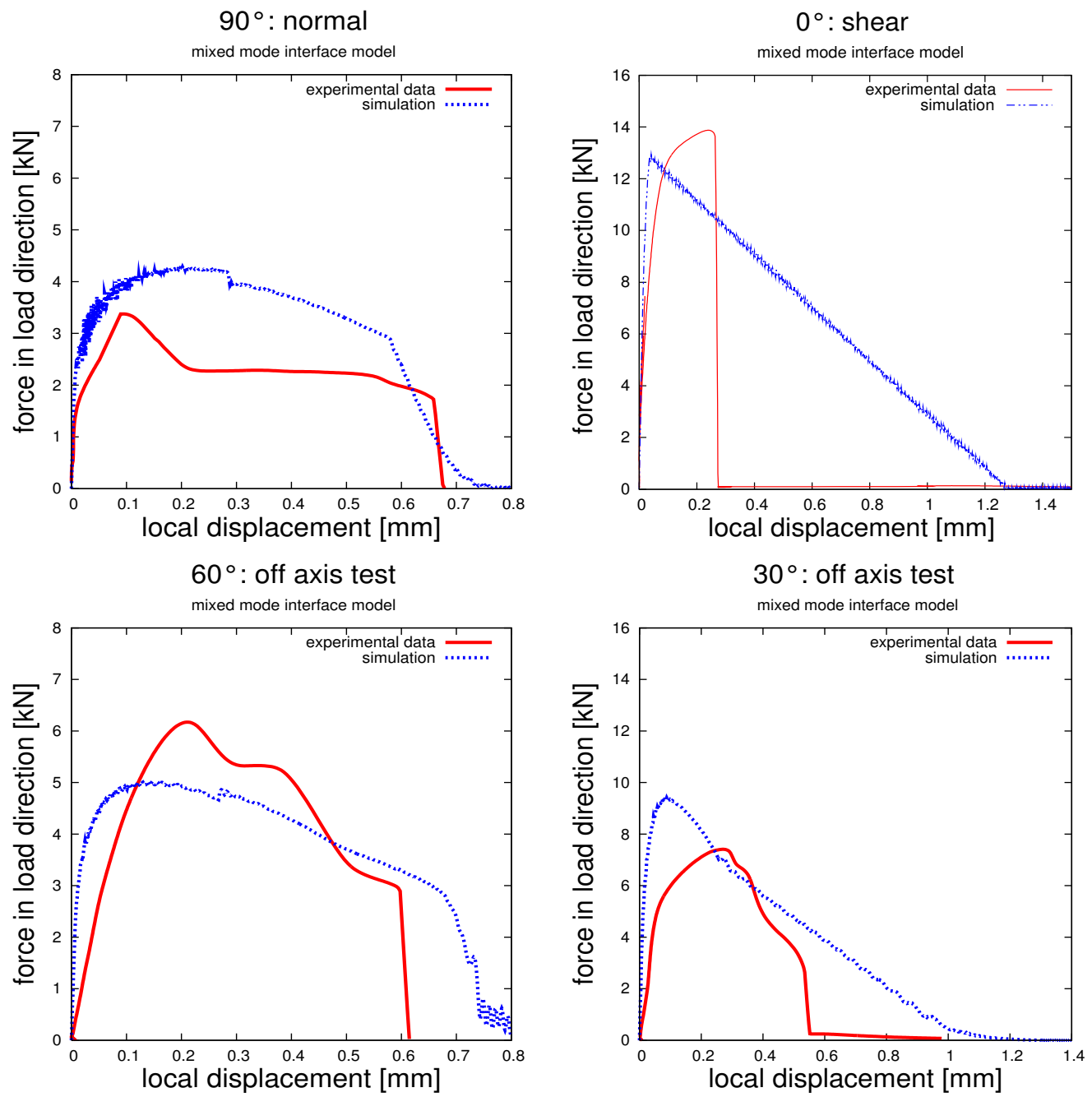

Figure 21. Comparison between experimental data and simulation results with mixedmode interface model for quasistatic loading: tension and shear tests with angles $90^{\circ}$ and $0^{\circ}$ (top) and off-axis tests with angles $60^{\circ}$ and $30^{\circ}$ (bottom). 
5E. Quasistatic loading of KS-II test. The numerical analysis of the KS-II test shows that the failure mechanism of the specimen is very complex. The thickness of the adherents is only $1.2 \mathrm{~mm}$ and, therefore, the relatively thin sheet metals are bent in two directions during the loading process. Additionally, the thickness of the bonding layer varies at the edges of the U-shaped adherents due to the filling of the joint (see Figure 20). Because of these phenomena, the state of stress and strain in the adhesive layer is very inhomogeneous. Therefore, the onset of failure takes place in the center very locally and spreads out continuously throughout the entire bonded area.

The maximum load carrying capacity depends on the off-axis angle and is largest in the cases of shear loading and minimal under normal loading. The peak values of the forces from the experimental and numerical analyses are of the same order of magnitude for both models (see Figures 21 and 22). However,
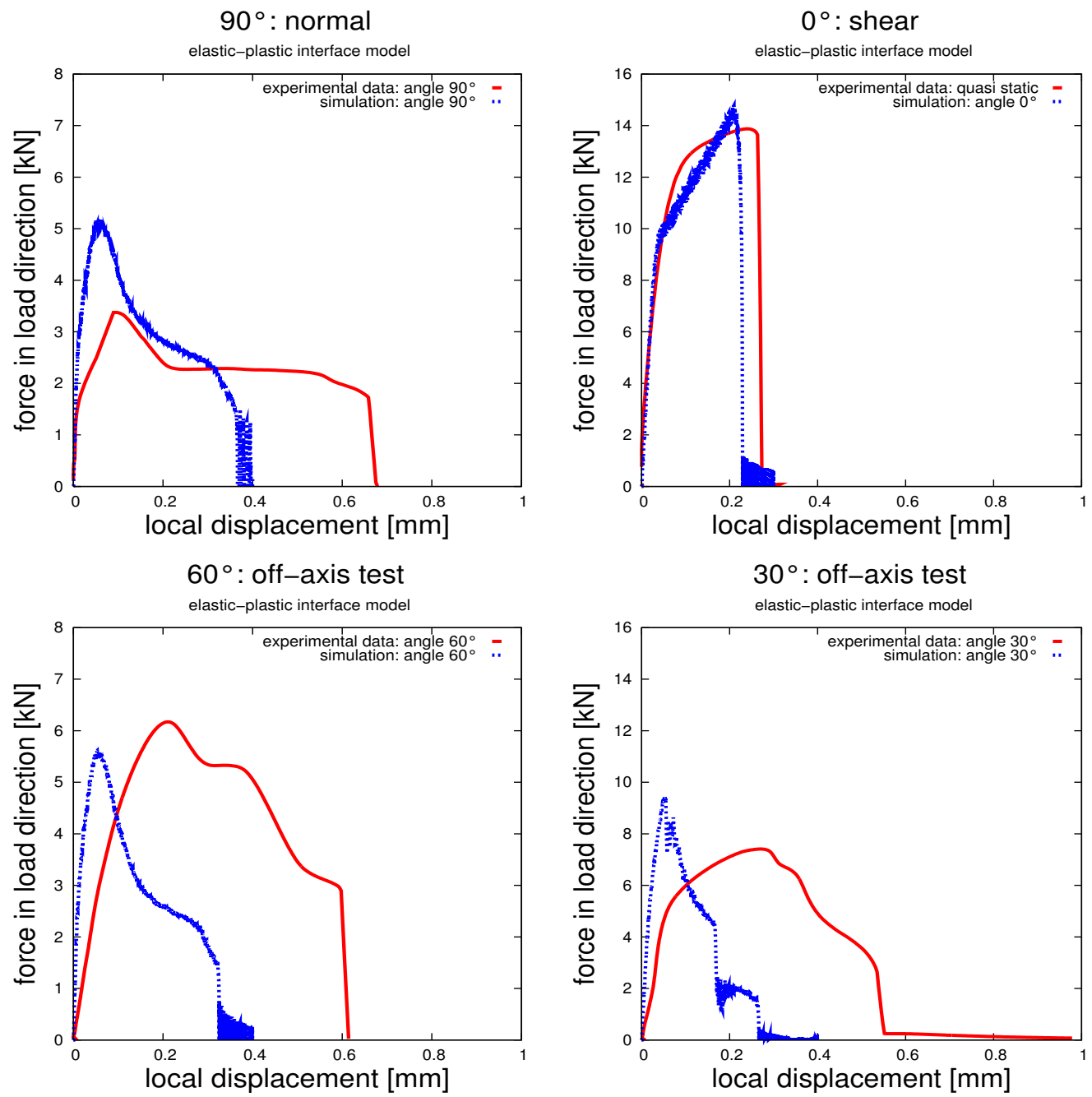

Figure 22. Comparison between experimental data and simulation results with elasticplastic interface model for quasistatic loading: tension and shear tests with angles $90^{\circ}$ and $0^{\circ}$ (top) and off-axis tests with angles $60^{\circ}$ and $30^{\circ}$ (bottom). 
the courses of the load-deflection diagrams from the test and the simulation in the case of shear loading $\left(0^{\circ}\right)$ differ in the postcritical range. As in the mixed-mode approach, the elastic-plastic interface model describes the mechanical behavior of the bonded joint in all four load cases reasonably well (Figure 22). The load-deflection diagrams of the load cases $30^{\circ}, 60^{\circ}$, and $90^{\circ}$ are more ductile in the test than in the simulations. The predicted peak values in all cases are in the range of the experimental data. The corresponding local displacement jumps between the two clamping devices are underestimated at both critical states, namely at the location of the maximum force and at complete failure in most load cases.

5F. Dynamic loading of KS-II test. The rate-dependent material behavior of the adhesive layer becomes significant in crash analyses. The rate dependency of the models, presented in (2-18), is quantitatively
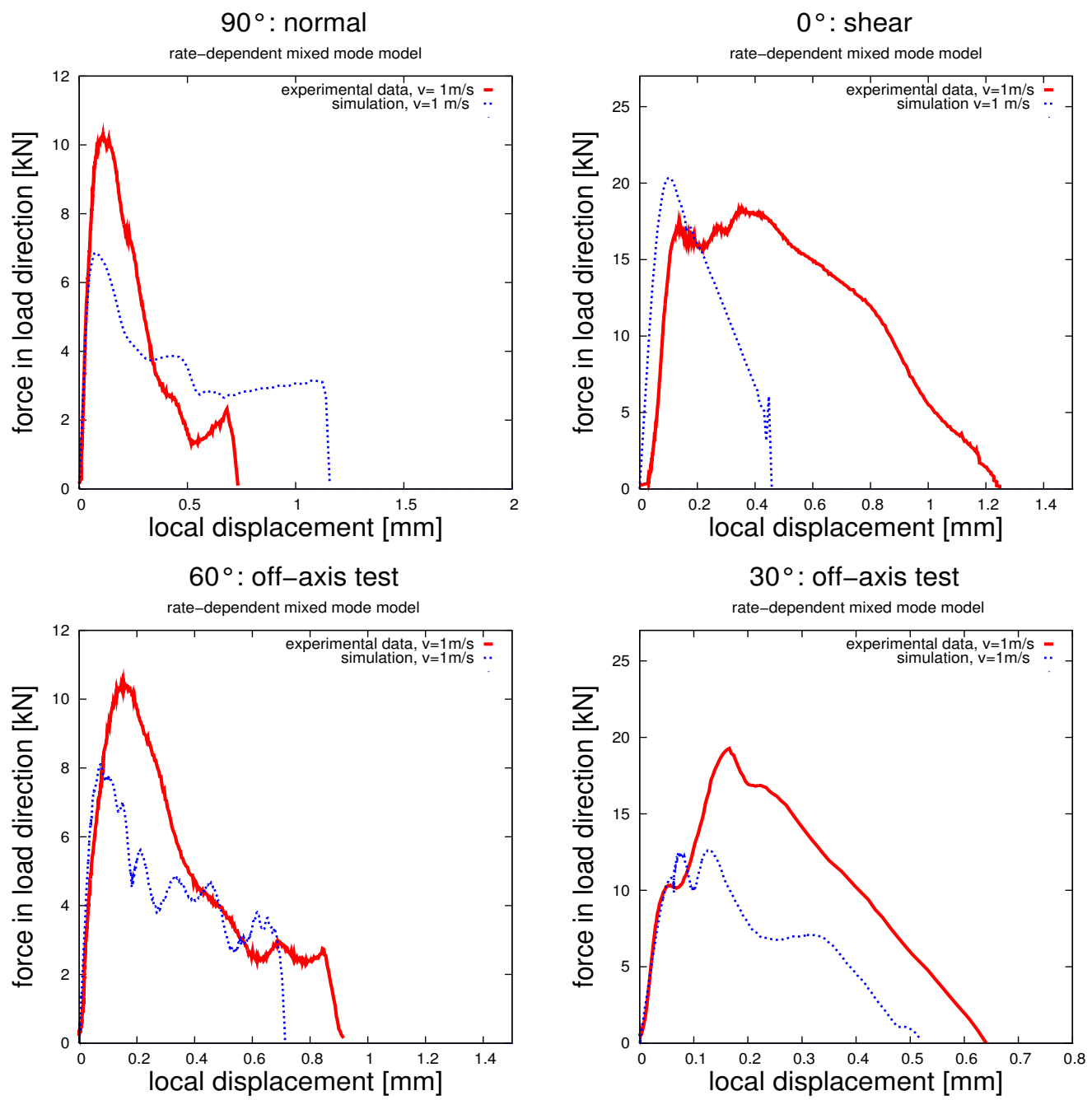

Figure 23. Comparison between experimental data and simulation results with mixedmode model for velocity $v=1.0 \mathrm{~m} / \mathrm{s}$ : tension and shear test with angles $90^{\circ}$ and $0^{\circ}$ (top), and off-axis tests with angles $60^{\circ}$ and $30^{\circ}$ (bottom). 
defined with the reference value $\dot{\Delta}_{0}=10^{-4} 1 / \mathrm{s}$ and with the parameter $C$, which is set equal to the slope of the graph for the linear regression in Figures 10 and 11: $C=m=0.076$. Because of the ratedependent influence of the adhesive, the KS-II specimens are tested dynamically. The tests are performed with tensile loading under four different off-axis angles as given above. The load-displacement curves are determined from the measured data for the displacements and the internal forces versus time. The experimental results from the tests in [Schlimmer et al. 2008] are shown in Figures 23 and 24 for a loading velocity of $v=1.0 \mathrm{~m} / \mathrm{s}$. Due to the rate-dependency of the adhesive, the peak value of the force increases clearly with a larger loading velocity in comparison to the ones of the quasistatic cases in Figures 21 and 22.

The mechanical behavior of the KS-II specimen under pure normal and combined loading with respect
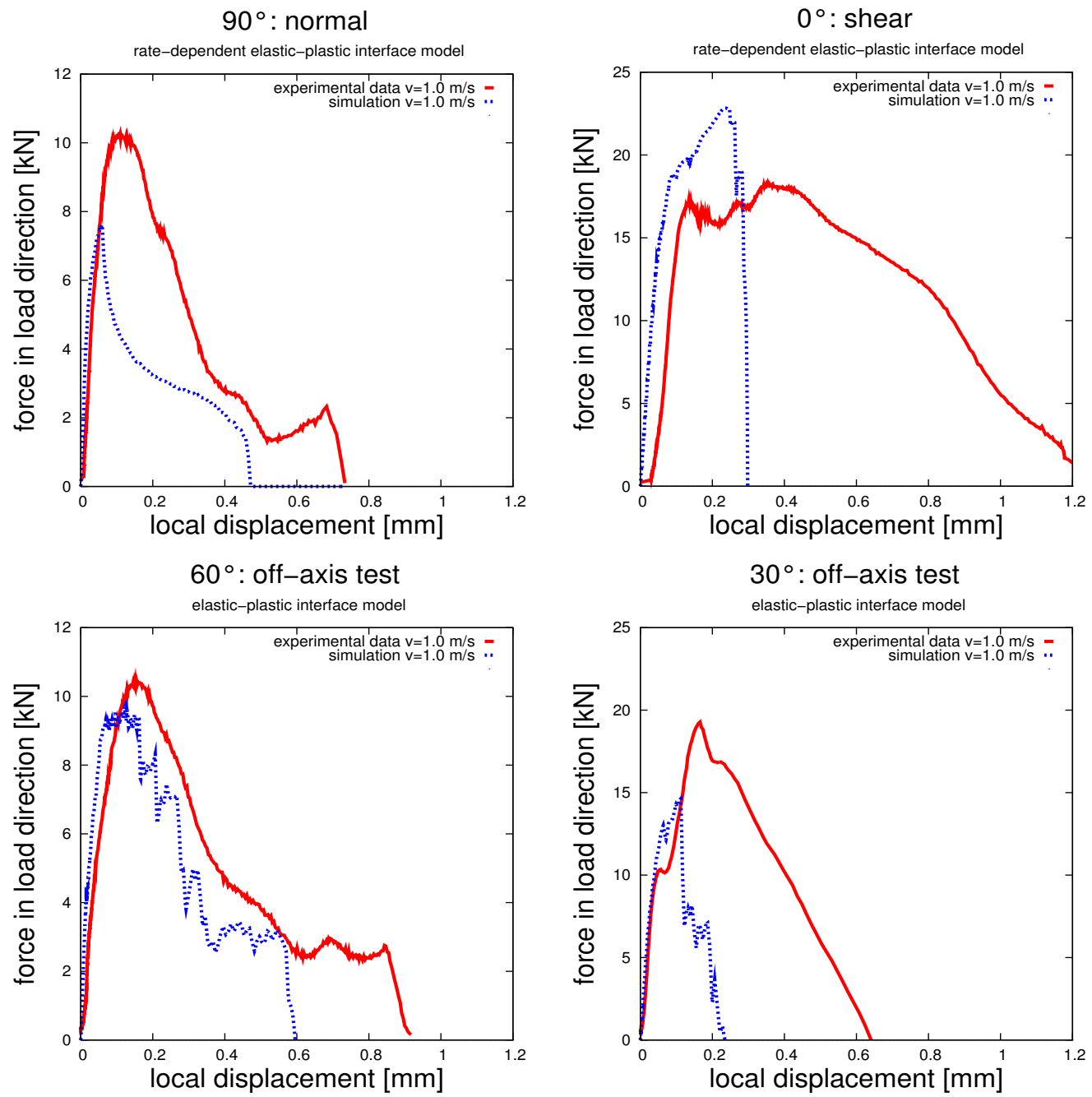

Figure 24. Comparison between experimental data and simulation results with elasticplastic interface model for velocity $v=1.0 \mathrm{~m} / \mathrm{s}$ : tension and shear test with angles $90^{\circ}$ and $0^{\circ}$ (top), and off-axis tests with angles $60^{\circ}$ and $30^{\circ}$ (bottom). 
to the direction of the adhesive layer is investigated in Figure 23 by comparing the finite element results of the mixed-mode fracture model to the experimental data. The theoretical solution and the test data are in fairly good agreement.

The results of the numerical analysis with Anand's traction-separation equations, extended to ratedependency, are graphically represented in Figure 24 for the four loading angles and a velocity of $v=1.0 \mathrm{~m} / \mathrm{s}$ for the separation of the two steel parts. The experimental data are added to the predicted load-displacement curves. In the case of shear loading, the ultimate forces in the experiment and the simulation agree well, but complete failure is detected at a much smaller relative displacement in the analysis with the traction-separation model than in the test. For the case of combined loading, the maximum forces differ more than in the diagrams for shear loading; however, the postcritical parts of the force-displacement curves agree better. A more reliable validation of the test data with the theoretical results is under way. One source of error is the force, measured far away from the adhesive layer, as already mentioned, and compared to the stress resultant of the adhesive layer. In contrast to the quasistatic case the entire test control unit should be modeled from the lower clamping part up to the measurement device for the force in the case of dynamical loading. The internal force, calculated at the position of the measurement cell, must be compared to the experimentally found value.

Another uncertainty is the exact reproduction of equal mechanical properties for the adhesive layer. The liquid glue solidifies under heating of the entire specimen in the successive curing process. It is difficult to guarantee a specified quality of the adhesive bond with strength and fracture strain within a small interval of tolerance.

\section{Summary and outlook}

The similarities of interface models for the analysis of delamination and fracture of adhesive layers between relatively stiff parts have been outlined and discussed with regard to the validation of simulated results from experimental tests. Two different approaches for the modeling of thin adhesive layers under crash loading conditions have been briefly outlined. An existing mixed-mode fracture model is extended to account for rate-dependent strength and damage and failure of the adhesive bond. Alternatively, an elastic-plastic interface model with a traction-separation equation can be used to describe the effective bonding behavior. Although the interface elements may be massless an estimate of the critical time step for the interface elements can be given.

Comparison of the simulation results and the experimental data demonstrates the model's ability to capture the experimentally observed major effects of rate-dependent damage and failure. The numerical approximation of the experimental data must be still improved, for example, by modeling the entire control unit and by better matching the experimental data. In order to draw conclusions from the simulation at hand for the crashworthiness analysis of vehicle bodies, the finite-element idealization for the KS-II test has to be simplified by reducing the number of elements considerably.

In addition to the development of an application oriented substitute model for the adhesive layer, the determination of adequate constitutive parameters for more effective substitute models is another important task of the current research project. Finally, the models developed so far should be applied to the simulation of a B-pillar in a car body, which will be investigated experimentally by another research partner. 
Acknowledgments. We gratefully acknowledge the provision of test data by Prof. Michael Schlimmer, of the University of Kassel, Prof. Ortwin Hahn, of the University of Paderborn, and Dr. Markus Brede, of the Fraunhofer-Institut für Fertigungstechnik und Angewandte Materialforschung (IFAM), Bremen, as well as helpful discussions with Dr. Olaf Hesebeck, also of IFAM.

\section{References}

[Aliyu and Daniel 1985] A. A. Aliyu and I. M. Daniel, "Effects of strain rate on delamination fracture toughness of graphite/ epoxy", pp. 336-348 in Delamination and debonding of materials (Pittsburgh, PA, 1983), edited by W. S. Johnson, ASTM Special Technical Publication 876, American Society for Testing and Materials, Philadelphia, PA, 1985.

[Andersson and Stigh 2004] T. Andersson and U. Stigh, "The stress-elongation relation for an adhesive layer loaded in peel using equilibrium of energetic forces", Int. J. Solids Struct. 41:2 (2004), 413-434.

[Barenblatt 1959] G. Barenblatt, "The formation of equilibrium cracks during brittle fracture: General ideas and hypotheses. Axially-symmetric cracks", J. Appl. Math. Mech. 23:3 (1959), 622-636.

[Beer 1985] G. Beer, "An isoparametric joint/interface element for finite element analysis", Int. J. Numer. Methods Eng. 21:4 (1985), 585-600.

[Brede and Hesebeck 2005] M. Brede and O. Hesebeck, "Verformungs- und Versagensverhalten von Klebverbindungen: Grundversuche für das Kohäsivzonenmodell”, Bericht 1-13-D-2005-09-0, Fraunhofer-Institut für Fertigungstechnik und Angewandte Materialforschung (IFAM), Bremen, for Research Project P676 of the Foundation "Stahlanwendungsforschung", FOSTA (Forschungsvereinigung Stahlanwendung e.V.), Düsseldorf, 2005.

[Brewer and Lagace 1988] J. C. Brewer and P. A. Lagace, "Quadratic stress criterion for initiation of delamination”, J. Compos. Mater. 22:12 (1988), 1141-1155.

[Chen et al. 1999] J. Chen, M. Crisfield, A. J. Kinloch, E. P. Busso, F. L. Matthews, and Y. Qiu, "Predicting progressive delamination of composite material specimens via interface elements", Mech. Compos. Mater. Struct. 6:4 (1999), 301-317.

[Dávila and Camanho 2001] C. G. Dávila and P. P. Camanho, "Decohesion elements using two and three-parameter mixedmode criteria", Technical report 20020010916, NASA Langley Research Center, Hampton, VA, 2001, Available at http:// tinyurl.com/NASA-20020010916. Presented at the American Helicopter Society, Hampton Roads Chapter, Structure Specialists' Meeting, Williamsburg, VA, 2001.

[Dugdale 1960] D. S. Dugdale, "Yielding of steel sheets containing slits", J. Mech. Phys. Solids 8:2 (1960), 100-104.

[DYNA 1998] J. O. Hallquist, LS-DYNA theoretical manual, Livermore Software Technology Corporation, Livermore, CA, May 1998, Available at http://www.dynamax-inc.com/manuals/theory.pdf.

[DYNA 2006] LS-DYNA keyword user's manual, Version 971, Livermore Software Technology Corporation, Livermore, CA, 2006, Available at http://www.dynasupport.com/news/ls-dyna-971-manual-pdf.

[FEAP 2002] R. L. Taylor, FEAP, a finite element analysis program: theory manual, Version 7.4, University of California, Berkeley, CA, 2002, Available at http://www.ce.berkeley.edu/feap.

[Fiolka 2007] M. Fiolka, Theorie und Numerik volumetrischer Schalenelemente zur Delaminationsanalyse von Faserverbundlaminaten, Ph.D. thesis, Institute of Mechanics, Department of Mechanical Engineering, University of Kassel, 2007, Available at http://tinyurl.com/ThesisMarkFiolka.

[Fiolka and Matzenmiller 2007] M. Fiolka and A. Matzenmiller, "On the resolution of transverse stresses in solid-shells with a multi-layer formulation”, Commun. Numer. Methods Eng. 23:4 (2007), 313-326.

[Hahn et al. 1999] O. Hahn, J. R. Kurzok, and M. Oeter, "Prüfvorschrift für die LWF KS-2-Probe", Laboratorium für Werkstoffund Fügetechnik, Universität Paderborn, 1999.

[Hillerborg et al. 1976] A. Hillerborg, M. Modéer, and P.-E. Petersson, "Analysis of crack formation and crack growth in concrete by means of fracture mechanics and finite elements", Cem. Concr. Res. 6:6 (1976), 773-781.

[Hughes et al. 1979] T. J. R. Hughes, K. S. Pister, and R. L. Taylor, "Implicit-explicit finite elements in nonlinear transient analysis", Comput. Methods Appl. Mech. Eng. 17-18:1 (1979), 159-182. 
[Irons 1970] B. M. Irons, "Applications of a theorem on eigenvalues to finite element problems”, Technical report CR/132/70, University of Wales, Department of Civil Engineering, Swansea, 1970.

[Jendrny 2005] J. Jendrny, "Grundversuche an Klebstoffen und Klebverbindungen", Bericht 1-11-D-2005-01-0, Laboratorium für Werkstoff- und Fügetechnik (LWF), Universität Paderborn, for Research Project P676 of the Foundation "Stahlanwendungsforschung", FOSTA (Forschungsvereinigung Stahlanwendung e.V.), Düsseldorf, 2005.

[Johnson and Cook 1983] G. R. Johnson and W. H. Cook, "A constitutive model and data for metals subjected to large strains, high strain rates and high temperatures", pp. 541-547 in Proceedings of the 7th International Symposium on Ballistics (The Hague, 1983), Royal Institution of Engineers in the Netherlands, The Hague, 1983.

[Mi et al. 1998] Y. Mi, M. A. Crisfield, G. A. O. Davies, and H. B. Hellweg, "Progressive delamination using interface elements", J. Compos. Mater. 32:14 (1998), 1246-1272.

[Pinho et al. 2006] S. T. Pinho, L. Iannucci, and P. Robinson, "Formulation and implementation of decohesion elements in an explicit element code”, Compos. A Appl. Sci. Manuf. 37:5 (2006), 778-789.

[Schellekens and de Borst 1993] J. C. J. Schellekens and R. de Borst, "On the numerical integration of interface elements", Int. J. Numer. Methods Eng. 36:1 (1993), 43-66.

[Schlimmer 2003] M. Schlimmer, "Grundlagen zur Berechnung des mechanischen Verhaltens von strukturellen Klebverbindungen des Fahrzeugbaus", pp. 107-133 in Mechanisches Fügen und Kleben: Tagungsband 10. Paderborner Symposium Fügetechnik (Paderborn, 2003), edited by O. Hahn, University of Paderborn, Laboratorium für Werkstoff- und Fügetechnik, Paderborn, 2003.

[Schlimmer et al. 2002] M. Schlimmer, O. Hahn, and O.-D. Hennemann, "Methodenentwicklung zur Berechnung und Auslegung geklebter Stahlbauteile für den Fahrzeugbau”, Technischer Bericht AiF-Projekt P 593/07/2002, FOSTA (Forschungsvereinigung Stahlanwendung e.V.), Düsseldorf, 2002.

[Schlimmer et al. 2008] M. Schlimmer, A. Matzenmiller, R. Mahnken, O. Hahn, K. Dilger, P. Gumbsch, K. Thoma, and O.-D. Hennemann, "Methodenentwicklung zur Berechnung von höherfesten Stahlklebverbindungen des Fahrzeugbaus unter Crashbelastung", Final report of Research Project P676, FOSTA (Forschungsvereinigung Stahlanwendung e.V.), Düsseldorf, 2008.

[Su et al. 2004] C. Su, Y. J. Wei, and L. Anand, "An elastic-plastic interface constitutive model: application to adhesive joints", Int. J. Plast. 20:12 (2004), 2063-2081.

[Teßmer 2000] J. Teßmer, Theoretische und algorithmische Beiträge zur Berechnung von Faserverbundschalen, Ph.D. thesis, Leibniz Universität Hannover, Institut für Baumechanik und Numerische Mechanik, 2000.

[Tvergaard and Hutchinson 1994] V. Tvergaard and J. W. Hutchinson, "Toughness of an interface along a thin ductile layer joining elastic solids", Philos. Mag. A 70:4 (1994), 641-656.

[Tvergaard and Hutchinson 1996] V. Tvergaard and J. W. Hutchinson, "On the toughness of ductile adhesive joints", J. Mech. Phys. Solids 44:5 (1996), 789-800.

[Whitcomb 1986] J. D. Whitcomb, "Parametric analytical study of instability-related delamination growth", Compos. Sci. Technol. 25:1 (1986), 19-48.

Received 23 Jan 2008. Accepted 26 Aug 2009.

ANTON MATZENMILLER: amat@ifm.maschinenbau.uni-kassel.de

Institute of Mechanics, Department of Mechanical Engineering, University of Kassel, Mönchebergstraße 7, 34109 Kassel, Germany

Sebastian Gerlach: sebastian.gerlach@gmx.de

Institute of Mechanics, Department of Mechanical Engineering, University of Kassel, Mönchebergstraße 7, 34109 Kassel, Germany

MARK FIOLKA: Mark_Fiolka@gmx.de

Institute of Mechanics, Department of Mechanical Engineering, University of Kassel, Mönchebergstraße 7, 34109 Kassel, Germany 


\title{
JOURNAL OF MECHANICS OF MATERIALS AND STRUCTURES
}

\author{
http://www.jomms.org
}

\author{
Founded by Charles R. Steele and Marie-Louise Steele

\section{EDITORS} \\ Charles R. STEele \\ DAVIDE BIGONI \\ IWONA JASIUK \\ YASUHIDE SHINDO \\ Stanford University, U.S.A. \\ University of Trento, Italy \\ University of Illinois at Urbana-Champaign, U.S.A. \\ Tohoku University, Japan
}

\section{EDITORIAL BOARD}

H. D. BUI École Polytechnique, France

J. P. CARTER University of Sydney, Australia

R. M. Christensen Stanford University, U.S.A.

G. M. L. GLADWELL University of Waterloo, Canada

D. H. HodGES Georgia Institute of Technology, U.S.A.

J. HUTCHINSON Harvard University, U.S.A.

C. HwU National Cheng Kung University, R.O. China

B. L. KariHaloo University of Wales, U.K.

Y. Y. KIM Seoul National University, Republic of Korea

Z. Mroz Academy of Science, Poland

D. PAMPlonA Universidade Católica do Rio de Janeiro, Brazil

M. B. RUBIN Technion, Haifa, Israel

A. N. SHUPIKov Ukrainian Academy of Sciences, Ukraine

T. TARNAI University Budapest, Hungary

F. Y. M. WAN University of California, Irvine, U.S.A.

P. WRIGGERS Universität Hannover, Germany

W. YANG Tsinghua University, P.R. China

F. ZIEGLER Technische Universität Wien, Austria

\section{PRODUCTION}

\section{Paulo Ney de Souza Production Manager \\ SheIla Newbery Senior Production Editor \\ SILVIO LEVY Scientific Editor}

See inside back cover or http://www.jomms.org for submission guidelines.

JoMMS (ISSN 1559-3959) is published in 10 issues a year. The subscription price for 2010 is US $\$ 500 /$ year for the electronic version, and \$660/year (+\$60 shipping outside the US) for print and electronic. Subscriptions, requests for back issues, and changes of address should be sent to Mathematical Sciences Publishers, Department of Mathematics, University of California, Berkeley, CA 94720-3840.

JoMMS peer-review and production is managed by EditFLOW ${ }^{\mathrm{TM}}$ from Mathematical Sciences Publishers.

PUBLISHED BY

mathematical sciences publishers

http://www.mathscipub.org

A NON-PROFIT CORPORATION

Typeset in LATEX

CCopyright 2010. Journal of Mechanics of Materials and Structures. All rights reserved. 


\title{
Journal of Mechanics of Materials and Structures
}

\author{
Volume 5, No. 2 February 2010
}

A critical analysis of interface constitutive models for the simulation of delamination in composites and failure of adhesive bonds

Anton Matzenmiller, Sebastian Gerlach and Mark Fiolka

185

Computational studies of collagen fibril biominerals using a virtual internal bond

model with extrinsic length scale

Ganesh Thiagarajan and Kavita Deshmukh

The simulation of stochastically excited viscoelastic systems and their stability

VADIM D. POTAPOV

Fundamental solutions for an inhomogeneous cross-anisotropic material due to horizontal and vertical plane strain line loads

Cheng-Der Wang, Jia-YAN Hou and WeI-Jer WANG

Mechanical and fracture analysis of welded pearlitic rail steels

Aldinton Allie, Heshmat A. Aglan and Mahmood Fateh

Rate dependence of indentation size effects in filled silicone rubber

Ramanjaneyulu V. S. TATIRAJU and ChUng-SOUK HAN

A novel application of a laser Doppler vibrometer in a hèalth monitoring system

DAVOOD REZAEI and FARID TAHERI

Energy absorption of a helicoidal bistable structure

Seubpong Leelavanichkul, Andrej Cherkaev, Daniel O. Adams

and FLORIAN SOLZBACHER

Decay properties of solutions of a Mindlin-type plate model for rhombic systems

Francesca Passarella, Vincenzo Tibullo and VitTorio Zampoli

A consistent refinement of first-order shear deformation theory for laminated composite and sandwich plates using improved zigzag kinematics Alexander Tessler, Marco Di Sciuva and Marco Gherlone 